\title{
Gestão de museus a partir da aplicação da Avaliação Pós-Ocupação. O caso do Museu Histórico e Cultural de Jundiaí, São Paulo
}

Management of museums based on the Post-Occupancy Evaluation appliance. The case of the Historical and Cultural Museum of Jundiaí, São Paulo

https://doi.org/10.1590/1982-02672020v28e05

RAISSA MELO DE SOUZA 1

https: / / orcid.org/0000-0002-6769-1921

Universidade de São Paulo / São Paulo, SP, Brasil

\section{SHEILA WALBE ORNSTEIN²}

https://orcid.org/0000-0002-5684-921X

Universidade de São Paulo / São Paulo, SP, Brasil

RESUMO: No Brasil há poucas pesquisas sobre espaços museológicos que contribuem efetivamente para a gestão destes espaços e muito menos pesquisas com base em levantamentos in situ que priorizam o ponto de vista dos usuários dos museus, sejam estes visitantes, sejam funcionários, como importante estratégia para a conservação, a manutenção e a operação do edifício, do acervo e dos ambientes externos, mitigando, dessa forma, os riscos envolvidos. $\bigcirc$ artigo parte desse pressuposto e descreve como a Avaliação PósOcupação (APO), um conjunto de métodos e técnicas que abrange a aferição da satisfação dos usuários e a verificação do desempenho físico dos ambientes, pode contribuir na formulação de diagnósticos e de recomendações com vistas à manutenção e à conservação consistentes para o caso de ambientes internos e externos antigos e que abrigam acervos. Para tanto, adotou-se como objeto de estudo exploratório o Museu Histórico e Cultural de Jundiaí - o Solar do Barão - para demonstrar a aplicabilidade da APO no caso de edifícios e espaços exteriores patrimoniados e colocar em discussão seus procedimentos metodológicos como alternativa de planejamento estratégico para museus, relacionando

\begin{abstract}
1. Graduanda da Faculdade de Arquitetura e Urbanismo da Universidade de São Paulo (FAU USP). E-mail: $<$ raissa.melo.souza@usp.br>

2. Professora Titular da Faculdade de Arquitetura e Urbanismo da Universidade de São Paulo - FAU USP e bolsista produtividade do Conselho Nacional de Desenvolvimento Científico e Tecnológico - CNPq. E-mail: <sheilawo@usp.br>
\end{abstract}


a conservação do edifício, do acervo e dos ambientes externos, com o acolhimento e a sensação de pertencimento dos usuários. Ao final e como resultados da APO aplicada em 2018 nesse caso em particular, apresenta-se um conjunto de recomendações técnicoespaciais e construtivas, para o conjunto edificado e ajardinado em questão e faz-se uma reflexão crítica sobre a necessidade de incorporar procedimentos de manutenção e de uso de espaços museológicos em suas rotinas operacionais e também utilizar esses resultados, sistematicamente organizados, para realimentar futuras readequações do próprio estudo de caso e, de forma ampliada, diretrizes para projetos arquitetônicos. Nessa perspectiva, o artigo destaca a importância do arquiteto especialista nas equipes que desenvolvem os projetos destinados ao restauro e à modernização desses espaços, bem como naquelas equipes que realizam a sua gestão, no decorrer do uso.

PALAVRAS-CHAVE: Espaço Museológico. Usuário. Avaliação Pós-Ocupação. Gestão de Facilidades.

ABSTRACT: In Brazil, there are few researches about museums that contribute more effectively to the management of these facilities and much less researches based on in situ surveys that priorize museum users, whether visitors or staff as an important conservation and maintenance strategy of the building, the collection and the outdoor environments, thus mitigating the risks involved. The article starts from this assumption and describes how Post-Occupancy Evaluation $(\mathrm{POE})$, a set of methods and techniques that encompasses the measurement of user perception and satisfaction and the verification of the physical performance of environments can contribute to address diagnoses and recommendations for consistent maintenance and upkeep for older indoor and outdoor collections (including the building itself). To this end, the Jundiaí Historical and Cultural Museum - Solar do Barão - sited at the State of São Paulo, Brazil, was adopted as an exploratory study object to demonstrate the applicability of POE in the case of heritage buildings and their outdoor spaces and to discuss its methodological procedures as an alternative to strategic planning for museums, relating the conservation of the building, the collection and the external environments, with the welcome and the sense of belonging of the visitors and staff. To sum up and as a result of the POE applied in 2018 in this particular case, we present a set of technical-spatial and constructive recommendations based on research, for the built and landscaped set in question and a critical reflection on the need for incorporate procedures for the maintenance, use and operation of museum on daily basis and also use these results, systematically organized, to feedback future readjustments of the case study itself and, broadly, guidelines for architectural designs. In this perspective, the article highlights the importance of the expert architect in the teams that develop the designs for the restoration and modernization of these environments, as well as in those teams that manage them during their use.

KEY-WORDS: Museum Environments. User. Post-Occupancy Evaluation (POE). Facilities Management. 
Este artigo é resultado de pesquisa desenvolvida junto ao Grupo de Pesquisa no Diretório do Conselho Nacional de Desenvolvimento Científico e Tecnológico (CNPq) Qualidade e Desempenho no Ambiente Construído. ${ }^{3}$ Na esteira da aplicação da Avaliação Pós-Ocupação (APO) em diversos edifícios antigos e de relevância patrimonial nos últimos dez anos, os pesquisadores deste grupo se propõem a verificar as condições físicas e de manutenção e a percepção e os níveis de satisfação relativamente a esses edifícios antigos que por si sós se constituem em acervos e que abrigam acervos móveis igualmente relevantes, com destaque especial para o caso dos Museus de História e de Belas Artes, mas não só.

Estas pesquisas têm como foco estudos de caso no Estado de São Paulo, mas seus diagnósticos e diretrizes, dado a quantidade expressiva de informações sistematizadas, podem colaborar com os programas de modernização, uso, operação e manutenção de outros edifícios no país com características construtivas e funcionais semelhantes e que foram adaptados com alterações significativas de usos, num dado período, para abrigar acervos museológicos.

As pesquisas sobre a aplicabilidade da APO em espaços museológicos surgem de forma mais enfática num momento em que situações como incêndios, enchentes e dificuldades para a manutenção do desempenho mínimo desses edifícios associadas a demandas por segurança, conforto e acessibilidade da parte de seus distintos usuários ganham contornos dramáticos no Brasil e no exterior. ${ }^{4}$

Para tanto, o artigo descreve detalhadamente a APO, que pode ser considerada como uma das linhas de pesquisa do denominado Projeto Baseado em Evidência ${ }^{5}$ - adotado no campo dos ambientes para a cura lou voltados para a saúde), mas passível de ser adotado em outros ambientes, como nos edifícios que abrigam museus -, aplicada num objeto de caso específico, o Museu Histórico e Cultural de Jundiaí (MHCJ).

O MHCJ foi definido como objeto de estudo por se situar no centro do município de Jundiaí, ser constituído por edifício principal do período colonial, apresentar uma ampliação no século XX e estar situado num amplo jardim, conjunto este muito representativo para a História da cidade e bastante utilizado pela população local e outros visitantes.

Para a aplicação da APO foi necessário realizar os levantamentos do terreno, da edificação e sua ampliação e do mobiliário e acervos internos e do mobiliário e da vegetação externos e registros físicos-cadastrais - estes até então inexistentes. Buscou-se também no Condephaató a documentação sobre o 
7. Cf. Ono et al. (2018).

8. Escola de Artes, Ciências e Humanidades da Universidade de São Paulo. processo cronológico de tombamento. A partir desses levantamentos físicos e documentais preliminares foram aplicados os multimétodos de APO, 7 incluindo os levantamentos, as análises e as considerações sobre o desempenho físico e a percepção e a satisfação dos usuários (visitantes, funcionários e especialistas).

Sobre o desempenho físico, foram elaborados os mapas de danos, aplicados os checklists sobre os sistemas construtivos, de segurança contra incêndio e sobre a acessibilidade e as observações sobre comportamentos e fluxos dos usuários.

Sobre a percepção e a satisfação dos diversos usuários, foram realizadas entrevistas e aplicados questionários com adultos, com base na autorização do Comitê de Ética em Pesquisa da EACH-USP. ${ }^{8}$

Tanto para a avaliação do desempenho físico como para aquela relativa à percepção e à satisfação dos usuários foram considerados como balizadores de qualidade as boas práticas nos campos da arquitetura e da engenharia, as normas de desempenho e a legislação vigente.

Os resultados dessa APO, quais sejam, o cruzamento entre a avaliação de desempenho físico versus a satisfação dos usuários, foram consubstanciados em quadros e mapas de diagnósticos e de recomendações que podem ser úteis aos tomadores de decisão ou gestores dos espaços museológicos, no caso deste objeto de estudo e de outros semelhantes com vistas a embasar diretrizes de projeto, a manutenção e a gestão predial associada às interfaces com as áreas externas e a vizinhança urbana próxima e o interior das edificações com base em evidências fundamentadas na pesquisa.

Entende-se que ao utilizar de forma rotineira tais procedimentos metodológicos, para auxiliar nas tomadas de decisão sobre projetos e manutenção, os gestores e suas equipes - desde que delas também façam parte arquitetos e engenheiros - poderão colaborar com a possibilidade de redução de riscos para pessoas e acervos.

\section{PLANO DE GESTÃO MUSEOLÓGICA: COM O USUÁRIO EM FOCO}

Numa sociedade organizada, um museu tem papéis muito importantes. Dentre eles, o de integrar sociedade e história através de exposições e ações educativas. Para realizar tais funções é imprescindivel que haja ambientes com desempenho físico adequado do ponto de vista técnico, acolhedores do ponto de vista da experiência do usuário e uma equipe treinada, capazes de receber 
os diversos visitantes, desde crianças até pessoas com deficiência e idosos, democratizando o acesso à educação, à cultura e à história.

Entretanto, ambientes habilitados e equipes compatíveis não são capazes, por si sós, de responderem a todas as demandas de um museu, apesar de seus esforços para tanto. É necessário um planejamento estratégico das ações a serem realizadas tanto no âmbito educacional e da aprendizagem, como também no âmbito da infraestrutura física e da manutenção dos ambientes internos e externos. Essas ações devem ser integradas e continuadas de modo a traçar protocolos de curto, médio e longo prazos.

Para criar e executar um plano de gestão integrado como esse anteriormente exposto, é necessário contar com uma equipe multidisciplinar composta por museólogos, educadores, arquitetos, engenheiros, designers, gestores de facilidades e outros profissionais. Os museólogos e educadores tratando primordialmente do âmbito educacional e os arquitetos e engenheiros, primordialmente do âmbito de infraestrutura e da manutenção do edifício. Como ações combinadas, esses âmbitos podem - e devem - se integrar a fim de produzir um conhecimento também multidisciplinar, como é o caso de muitos museus abrigados em edifícios antigos de valor histórico. Esses conhecimentos podem colaborar nas necessárias adequações e ajustes das interfaces entre meios urbano e edifício e seus ambientes externos, e entre edifício e ambientes expositivos e de reservas técnicas, infraestrutura e mobiliário.

No âmbito educacional, tanto as exposições quanto as ações educativas devem ser planejadas de acordo com a realidade do museu, tendo em vista a temática a ser tratada, os itens disponíveis no acervo, o público-alvo, o impacto social e espacial das ações - com base no fluxo de pessoas até o museu e no seu interior -, além da capacidade estrutural e espacial do edifício para receber tais ações e público extenso e diverso. Essas questões, embora sejam necessárias em todas as instituições museológicas, são de certo modo subjetivas - ainda que entremeadas por critérios técnicos -, pois sofrem variações conforme a realidade em que cada museu está inserido.

No âmbito da infraestrutura física e da manutenção do edifício, as questões tratadas são mais objetivas, pois o arquiteto e/ou engenheiro devem prezar sempre pelo conforto e pela segurança do usuário - visitantes e funcionários do museu - e também pela conservação do edifício, dos objetos expostos e daqueles em reserva técnica. Esses parâmetros são, em grande parte, normatizados e atendem a diretrizes dos órgãos de preservação do patrimônio, em níveis municipal, estadual e federal, e outras entidades de caráter nacional e internacional, sendo que várias delas contemplam diretrizes relativas à preservação de ambientes museológicos. 
9. ABNT (2015).

10. Corpo de Bombeiros... (2018a-1).

11. Instituto Brasileiro de Museus.

12. Cf. Ono; Moreira (2011)

13. Cf. G1 (2015).

14. Cf. G1 (2018).

15. Cf. Bermúdez (2019).

16. Cf. Fundação Darcy Ribeiro (2017) e Carvalho (2015).
No Brasil, muitos museus estão aquém do requerido em arcabouço normativo, desde questões de acessibilidade, associadas principalmente à NBR 9050, 9 até questões de segurança contra incêndio, por exemplo, associadas principalmente às Instruções Técnicas do Corpo de Bombeiros ${ }^{10} \mathrm{e}$ às questões de segurança patrimonial também associadas aos manuais do lbram ${ }^{11}$ como preconizam pesquisadores da área. ${ }^{12}$ Podemos notar situações adversas dessa natureza, por exemplo, no caso do Museu da Língua Portuguesa, na cidade de São Paulo, hoje em fase de restauro, mas que em 2015 foi atingido por incêndio de grandes proporções, ${ }^{13}$ ou mesmo no caso do Museu Nacional, na cidade do Rio de Janeiro, em 2018,14 dentre outros. Esses casos citados são exemplos da situação de diversos museus no Brasil, entretanto não é exclusividade de países em desenvolvimento, tal como pode-se observar nos acontecimentos da catedral de Notre Dame, Paris, que igualmente sofreu impacto de um grande incêndio em abril de 2019.15

A falta de manutenção e a infraestrutura precária no Brasil são problemas recorrentes em muitos edifícios antigos que abrigam museus, em que pesem algumas exceções e exemplos de uso de procedimentos e protocolos técnicos que minimizam a necessidade da manutenção corretiva e onerosa, como no caso da Casa de Rui Barbosa e seus jardins, situada na cidade do Rio de Janeiro. ${ }^{16}$

Por essas razões, neste caso em particular, pretendeu-se mostrar a aplicabilidade da APO no que diz respeito aos seus procedimentos metodológicos com vistas à aferição de critérios de desempenho e das potencialidades do ambiente museológico objeto de estudo, sob uma perspectiva técnico-construtiva, das espacialidades e da experiência dos usuários.

Destaca-se a relevância da gestão adequada dos ambientes museológicos para a preservação do seu conjunto arquitetônico e paisagístico, tendo os seus múltiplos usuários como protagonistas. Embora a gestão de facilidades, no caso de edifícios complexos em uso, como museus, seja muito reconhecida nos países desenvolvidos e um fator a ser considerado desde o processo de projeto, no Brasil poucos museus a adotam na sua plenitude. Ademais, no caso dos museus cuja gestão é feita pelo setor público, somam-se às dificuldades orçamentárias a eventual precariedade da infraestrutura e do sistema construtivo desses edifícios, salvo poucas exceções.

No caso do $\mathrm{MHCJ}$, foram apontadas, à época da pesquisa, a necessidade de ações de conservação, restauro e de modernização de sua infraestrutura, estrategicamente planejadas.

Por isso, a abordagem para esse exemplo específico, semelhante a tantos outros no caso brasileiro, é a prática da gestão da infraestrutura como fundamental 
para a preservação dos edifícios, seus ambientes externos e os acervos abrigados, tendo em mente a preocupação com a preservação da própria edificação, os acervos e a segurança e o acolhimento dos usuários, sejam visitantes, sejam funcionários.
17. Cf. Souza (2019).

18. Condephaat (1969, p. 69)

\section{DESCRIÇÃO DO OBJETO DE ESTUDO}

A pesquisa que originou este artigo teve como objeto de estudo o MHCJ - Solar do Barão, situado na cidade de Jundiaí, interior de São Paulo. Essa pesquisa de caráter de Iniciação Científica foi desenvolvida na Faculdade de Arquitetura e Urbanismo da USP no período de fevereiro de 2018 a janeiro de 2019.17

O MHCJ está situado no edifício denominado Solar do Barão (doravante denominado SBI, no centro da cidade de Jundiaí, interior de São Paulo. $O$ centro desse município é um polo comercial bastante intenso que atrai moradores tanto das áreas periféricas quanto de cidades vizinhas para compras de varejo, desde vestuário até eletrodomésticos, criando um grande fluxo de pessoas na região. Essa localização privilegia o museu, com potencial atrativo de novos visitantes. Em 2017 o museu apresentou cerca de 1.500 visitantes espontâneos por mês, sem contar os agendamentos com escolas e organizações sociais.

Segundo a direção do MHCJ, à época da realização da pesquisa, o SB teve sua construção iniciada pelo sargento-mor Antônio Queiroz Telles, pai do Barão de Jundiaí, e ocorreu em aproximadamente 1793. Em 1862, segundo a mesma fonte, foi finalizada a reforma da fachada e colocada essa data na guarnição de ferro da porta de entrada, indicativa da data de conclusão das obras, como era usual na época. Esta última data consta do processo de tombamento. ${ }^{18} \mathrm{O}$ Barão de Jundiaí, por sua vez, era um aristocrata cafeeiro do interior de São Paulo e possivelmente utilizava - Solar, à época, como uma espécie de casa de veraneio, com o fim principal de abrigar festas e reuniões políticas, não sendo ela a sua moradia cotidiana.

O edifício é predominantemente térreo, mas possui também um porão e está implantado num lote voltado para a praça central da cidade e construído em taipa de pilão. Em sua fachada principal apresenta dez janelas com uma porta em seu eixo de simetria que dá acesso à área interna do casarão (figura 1). À esquerda da fachada há outra porta que dá acesso aos fundos do lote onde hoje está implantado um jardim de cerca de $1.600 \mathrm{~m}^{2}$ (figura 2). Esse espaço externo é bastante visitado, especialmente pelas pessoas que trabalham na região 
em seu horário de almoço, que o utilizam como área de descanso e de sociabilidade. $\bigcirc$ edifício já sofreu diversas reformas, modificações e acréscimos. O mais significativo deles é uma ampliação, datada do século XIX, construída em tijolo de barro queimado. Apesar disso, ainda se encontram preservados muitos dos elementos construtivos originais, como alguns pisos, esquadrias, vidros decorados e muros divisórios do terreno em taipa de pilão.

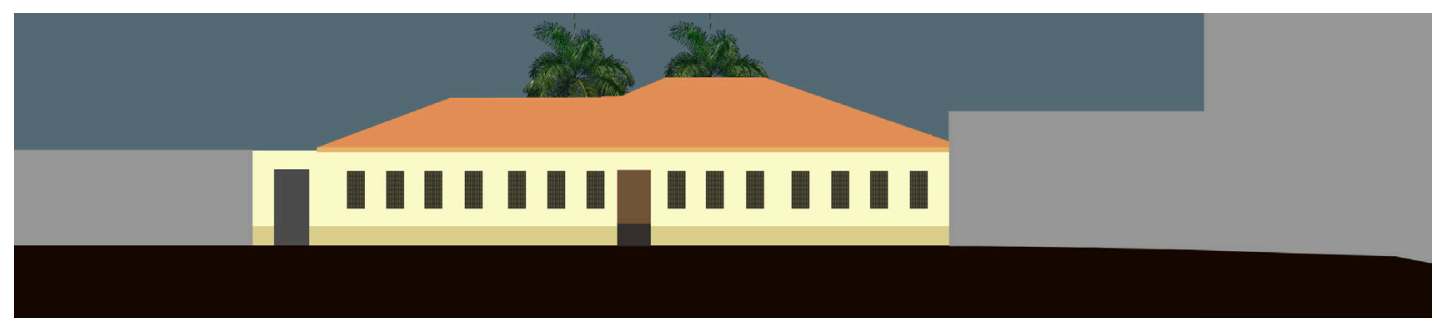

Figura 1 - Fachada do Solar do Barão e volumetria (em cinza claro) dos edifícios vizinhos. Trecho de modelo 3D. Fonte: elaboração própria, 2018.

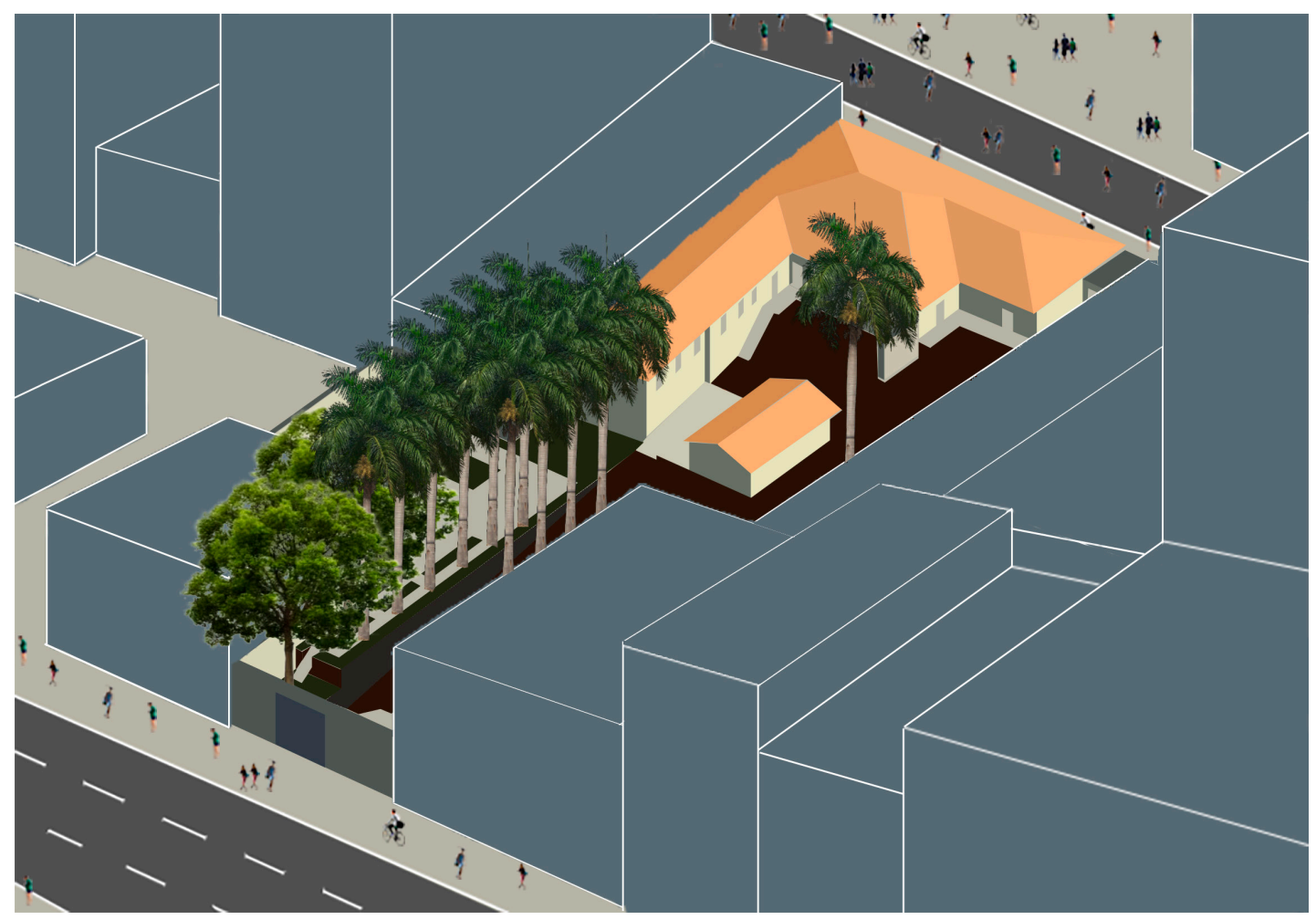

Figura 2 - Solar do Barão, jardim e volumetria dos edifícios vizinhos. Modelo 3D. Fonte: elaboração própria, 2018. 
O SB foi tombado pelo Condephaat em 1970 e, após análise documental realizada junto a esse conselho em 2 de outubro de 2018, foi possível ter acesso, para fins exclusivos de pesquisa acadêmica, aos documentos arquivados pelo estado referente ao processo de tombamento e conservação do SB inscrito sob o número 07857/69; resolução de tombamento de 13.03.1970; livro de tombo histórico: inscrição n. 12, p. 2, s. d. A partir desses documentos foram pontuadas as informações mais relevantes do processo de tombamento (figura 3), abaixo transcritas, sendo a primeira informação datada de 1969, e a última, de 1979.

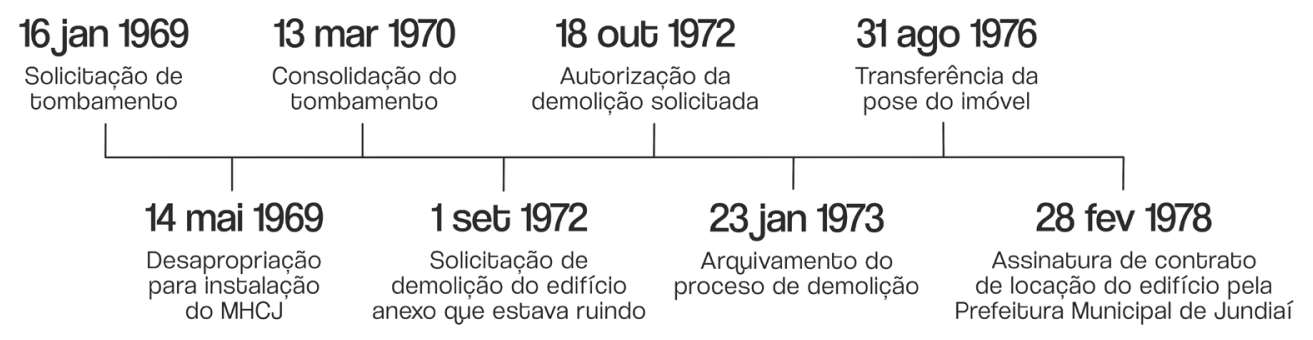

Figura 3 - Linha do tempo resumida. Fonte: elaboração própria, com base nos documentos constantes do processo de tombamento n. 07857/69 do SB junto ao Condephaat.

processo de tombamento teve início em 16 de janeiro de 1969, por solicitação do conselheiro do Condephaat Vinício Stein Campos e sob responsabilidade técnica de Luiz Saia, Abelardo Gomes de Abreu e Agenor Goulart dos Reis Filho ${ }^{19}$ que, nos meses seguintes, fizeram a avaliação técnica do edifício. Em 14 de maio do mesmo ano, o então governador do Estado de São Paulo Roberto Costa de Abreu Sodré decretou a desapropriação do prédio e terreno do Solar do Barão para instalação do Museu Histórico e Cultural de Jundiaí - Decreto n 51.818 , de 14 de maio de 1969, publicado na Casa Civil. Em 13 de março de 1970 houve o tombamento, como monumento histórico, do imóvel denominado Solar do Barão sem definições precisas (publicado no Diário Oficial do Estado de São Paulo em 14 de março de 1970). Nos dois anos seguintes houve troca de cartas entre o Condephaat e a Prefeitura Municipal de Jundiaí, para reafirmar o que o tombamento do SB significava em termos técnicos, proibição de destruição, demolição, mutilação, alteração, reparação, pintura ou restauração do SB sem a autorização do Condephaat, bem como de obras em um raio de 300 m em torno do edifício.

Em $1^{\circ}$ de setembro de 1972 a Prefeitura Municipal de Jundiaí solicita junto ao Condephaat a demolição do prédio do SB que faz frente com a rua Rangel Pestana, fundo do lote (figura 4), por oferecer perigo aos transeuntes.
19. Onde lê-se de Agenor Goulart dos Reis Filho possivelmente seria Nestor Goulart Reis Filho, podendo ter ocorrido um equívoco na datilografia. O professor Nestor está envolvido com conselhos de conservação do patrimônio há muitas décadas e é citado outras vezes nos documentos desse processo de tombamento. Enquanto que Agenor Goulart dos Reis Filho, embora conste no documento, quando pesquisado em sites de buscas, não se vincula a nenhum tipo órgão de preservação do patrimônio ou à arquitetura e engenharia. 


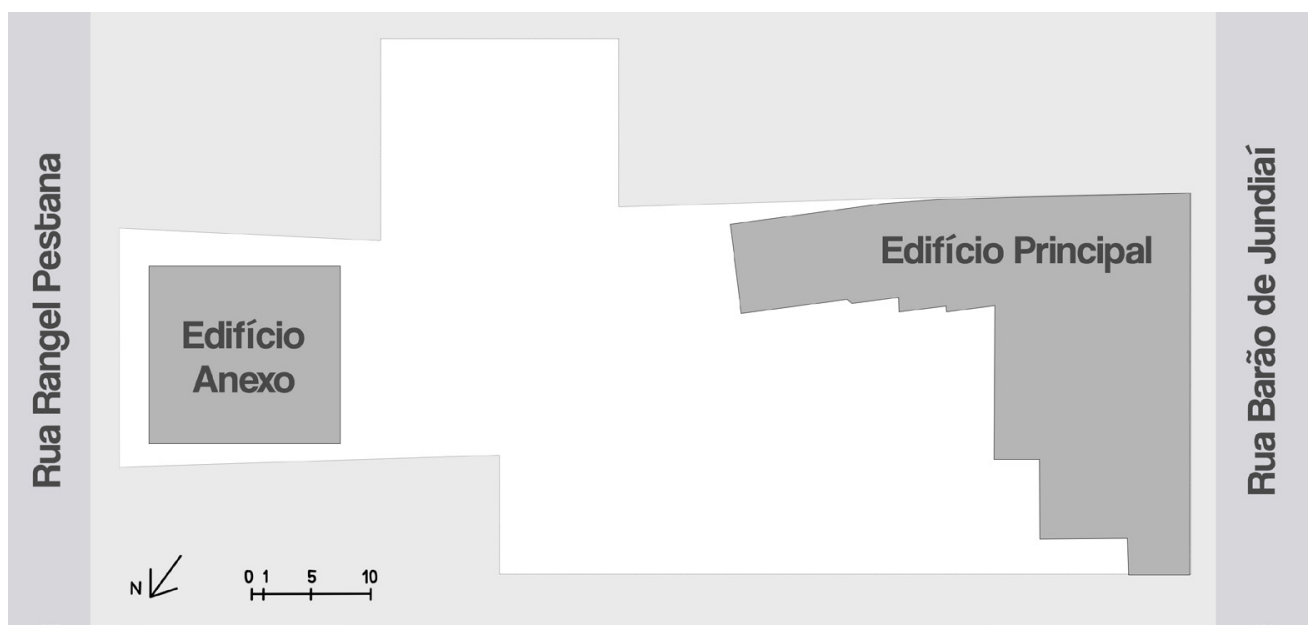

Figura 4 - Localização do edifício com risco de queda (edifício anexo) no lote e demolido nos anos 1970. Fonte: elaboração própria, 2018 , com base nos documentos textuais e nos registros fotográficos constantes dos documentos do processo de tombamento n. 07857/69 do SB.

Após algumas trocas adicionais de cartas insistindo na demolição do edifício anexo por oferecer risco aos transeuntes, em 18 de outubro de 1972 a demolição é autorizada pelo Condephaat, com o adendo do conselheiro professor Nestor Goulart Reis Filho, por não contrariar a compleição paisagística ou ferir o princípio ecológico, encerrando oficialmente e arquivando o processo legal para a demolição do edifício anexo ao Solar do Barão em 23 de janeiro de 1973.

Em 31 de agosto de 1976 a posse do imóvel é transferida para a Associação União Beneficente das Irmãs de São Vicente de Paulo de Gysegem, conforme testamento da antiga proprietária, mediante Matrícula n 3.000, do Livro 2-J, de Registro Geral, no $1^{\circ}$ Cartório de Registro de Imóveis da Comarca de Jundiaí, SP. Em 28 de fevereiro de 1978 a Prefeitura Municipal de Jundiaí estabelece um contrato de locação do SB com a Associação União Beneficente das Irmãs de São Vicente de Paulo de Gysegem.

Nos anos seguintes são registradas parcerias entre a Prefeitura de Jundiaí e a Associação União Beneficente das Irmãs de São Vicente de Paulo de Gysegem para manutenção do edifício Solar do Barão, parcerias essas que permanecem até os dias atuais.

A APO no MHCJ foi aplicada no conjunto edificado preservado (edifício principal, conforme demonstra a figura 4, anterior) e nos jardins, levantando os pontos positivos e aqueles a serem melhorados nos ambientes internos e externos do SB. 
PROCEDIMENTOS METODOLÓGICOS: A APLICAÇÃO DA AVALIAÇÃO PÓS-OCUPAÇÃO

A APO tem como objetivo central a realização da avaliação de ambientes em uso com base na avaliação de desempenho físico do edifício e, principalmente, da percepção e da satisfação dos usuários, sendo estes visitantes espontâneos, funcionários ou até mesmo pesquisadores, para propor melhorias e recomendações ao objeto de estudo de caso, ${ }^{20}$ visando também definir diretrizes, na medida do possível, para projetos futuros. ${ }^{21}$ Especialmente porque, mesmo que seja projetado de acordo com as normas e instruções técnicas, com a mais alta tecnologia de construção e seja executado da forma mais fidedigna possível ao projeto, se não se adequar aos usuários, o edifício não terá cumprido seu propósito. ${ }^{22}$

Sob esta perspectiva, estreitar a relação entre o museu e a comunidade perpassa, obrigatoriamente, pela adequação do ambiente físico, o qual deve atender o usuário de modo amplo, fazendo com que este usuário se sinta parte e, principalmente, queira fazer parte desses ambientes. Portanto, analisar questões de acessibilidade, conforto térmico, acústico, segurança, estética, visibilidade da exposição, entre outras, é fundamental. ${ }^{23}$ A preservação e a acessibilidade precisam caminhar de forma integrada entre si e avançar em seu diálogo na criação de soluções de acesso e circulação que não inibam a participação de ninguém, quaisquer que sejam suas características sensoriais, cognitivas e motoras. ${ }^{24}$

A APO pode ser aplicada para a avaliação de qualquer objeto, ambiente ou edifício, pois seus métodos e técnicas são facilmente adaptáveis a novas realidades. As pesquisas acadêmicas nas áreas de arquitetura, engenharia e construção se desenvolvem sobre as mais diversas formas de ocupação do espaço, desde escolas primárias ${ }^{25}$ a complexos hospitalares. ${ }^{26}$ Particularmente a APO, no Brasil, embora tenha ainda limitações, tem se desenvolvido no âmbito acadêmico através de pesquisas, de ensino e de algumas consultorias. ${ }^{27}$

Mais recentemente, devido aos avanços tecnológicos, alguns aspectos da APO estão se aperfeiçoando na direção da automação do processo de coleta e de processamento de dados, possibilitando um levantamento mais detalhado e ágil do objeto de estudo. ${ }^{28}$ Por sua vez, o escaneamento 3D do edifício, bem como a possibilidade de manuseá-lo, no futuro, com a modelagem 4D BIM - Building Information Modeling, ${ }^{29}$ por exemplo, são avanços recentes e estão permitindo, por meio de ferramentas computacionais, a gestão ambiental integrada, simulando ambientes, possibilitando a inserção de documentos técnicos e de orçamentos e até mesmo auxiliando na verificação de pontos críticos de manutenção e de operação. ${ }^{30}$ Sob essa perspectiva, a plataforma
20. Cf. Elali (2010).

21. Cf. Kowaltowski; Moreira (2008).

22. Penteado et al. (2018, p. 2018).

23. Voordt; Wegen (2013, p. 10).

24. Assis (2012, p. 7).

25. Cf. França (2011).

26. Cf. Thomazoni (2016).

27. Cf. Ono et al. (2018).

28. Cf. Ornstein (2017b).

29. Cf. Reyes; Campos; Hernandez (2013).

30. Cf. Bienvenido-Huertas et al. (2019). 
31. Presidência da República (2019)

32. Cf. Barros; Ruschel; Silva (2019), Paraizo (2016) e Pascoal Júnior (2019)

33. Revit é um software BIM para modelagem paramétrica usado em arquitetura, urbanismo, engenharia e design, pertencente à Autodesk.

34. Cf. Tinoco (2009)
BIM deve ser implementada por etapas, a partir de 2021 , no caso de todos os ambientes construídos e edifícios cuja gestão é ou será feita pelo setor público, ${ }^{31}$ incluindo, nesse caso, os museus sob a responsabilidade pública.

A plataforma BIM pode agregar a gestão de acervos imóveis (edifícios e jardins) e acervos móveis (objetos, esculturas, pinturas, por exemplo) e o monitoramento e as vistorias preliminares podem ser auxiliados por drones, sensores, assim como os estudos preliminares podem ser visualizados e avaliados por meio da realidade virtual ou aumentada. $\bigcirc$ BIM, além de possibilitar a compatibilização entre projetos de arquitetura e especialistas de forma mais assertiva, permite 0 compartilhamento de informações entre os profissionais integrantes da equipe em tempo real, nos moldes do projeto participativo ou do codesign. ${ }^{32}$

\section{BASES GRÁFICAS PARA SUPORTE DA PESQUISA}

Nessa pesquisa, em particular e à título de exemplificação, foi elaborado um modelo 3D do lote e seu edifício na plataforma Revit ${ }^{33}$ (figuras 1 e 2), muito vinculado ao BIM e que permite, com a atualização frequente das informações, fazer a gestão das ações, desde aquelas em nível de pré-projeto, passando pelo restauro, até as operações e manutenções no decorrer do uso.

As bases gráficas são a principal fonte de informação sobre a edificação no que se refere a dimensões, sistema construtivo, instalações, infraestrutura e programa de necessidades do edifício. Se mantidas atualizadas, são muito úteis para o planejamento de ações de reforma e restauro, além de contribuir em casos emergenciais relacionados a manifestações patológicas, para identificação de pontos críticos na edificação, a partir de séries históricas de ocorrências e de soluções e especificações técnicas adotadas para dirimir ou resolver problemas dessa natureza. No caso de museus, as bases gráficas são ainda mais importantes - se atualizadas - por permitir o planejamento estratégico dos leiautes das exposições e da roła segura e acessível dos usuários pelo edifício.

$\mathrm{Na} A P O$, as bases gráficas são importantes não só para a avaliação das questões acima citadas, mas também por serem documentos que, se mantidos atualizados de modo sistêmico e periódico, permitem a identificação de possíveis alterações no edifício e facilitam a investigação das causas de eventuais manifestações patológicas e a elaboração dos mapas de danos. ${ }^{34}$ Além disso, após o cruzamento da avaliação de desempenho físico da edificação e da satisfação dos usuários, é 
possível desenvolver mapas de diagnósticos e recomendações e planejar ações de curto, médio e longo prazos, com base nos níveis de riscos apresentados.

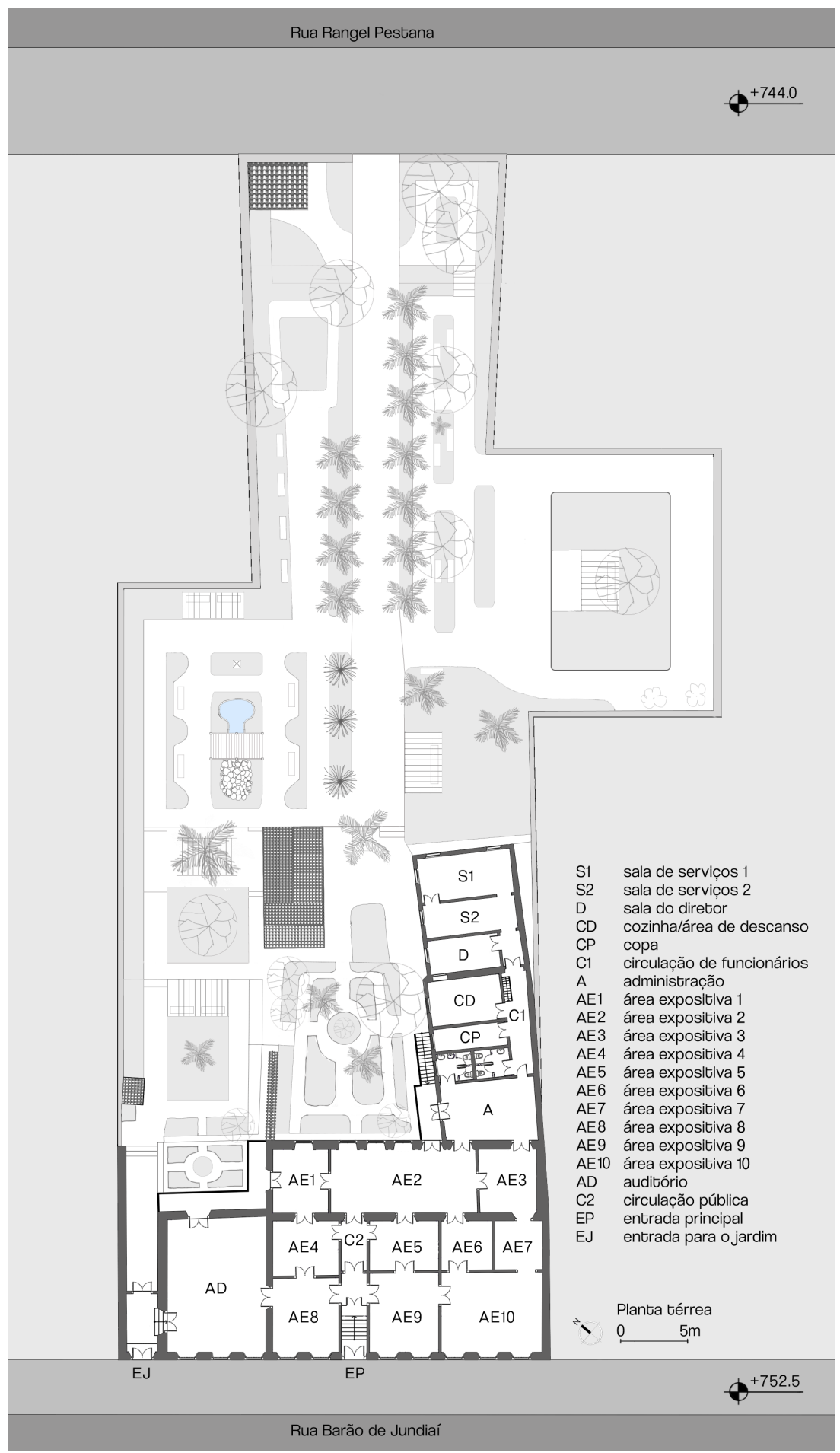

Figura 5 - Planta do Solar do Barão. Fonte: planta do piso térreo cedida pelo $M H C$, sem autoria identificada e adaptada e atualizada relativamente aos usos dos ambientes internos e dos jardins e à conferência in situ de medidas internas e dos jardins pela pesquisadora, 2018. 
No desenvolvimento da pesquisa, porém, constatou-se que o MHCJ não dispunha de bases gráficas do lote, do jardim nem do arranjo espacial interno da edificação. Foi disponibilizada apenas uma planta parcial do lote com o pavimento térreo do edifício e medidas internas. Para dar andamento à pesquisa, foi realizado o as built completo, abrangendo desde os ambientes internos do museu até o jardim (figura 5).

\section{DESENVOLVIMENTO DOS MAPAS DE DANOS}

mapa de danos é um documento síntese das informações levantadas sobre o desempenho físico da edificação em que são pontuadas as alterações e manifestações patológicas na estrutura, nos componentes construtivos e nos revestimentos. ${ }^{35}$ A elaboração do mapa de danos é, portanto, essencial para compreender os possíveis danos da edificação, orientando o planejamento das ações de conservação e restauro do edifício.

Na pesquisa, após a realização do as builte da avaliação do desempenho físico, foi elaborado um mapa de danos síntese com base em três principais manifestações patológicas, identificadas como mapeáveis, sendo elas: as fissuras, os descascados ou falta de tinta e os pontos com infiltrações de água de chuva ou decorrentes de instalações hidráulicas degradadas. Além do mapa síntese, foram elaborados mais três mapas de danos, um para cada manifestação patológica, a fim de facilitar a compreensão dos temas mencionados. Alguns outros temas identificados no checklist e nas entrevistas não eram totalmente mapeáveis, mas estão presentes no quadro síntese e nos mapas de diagnósticos e recomendações, como é o caso das instalações elétricas do edifício que se encontravam fora dos padrões técnicos atuais, apresentando risco aos usuários e à edificação. Após realização da avaliação física do edifício, ainda no período da pesquisa, o MHCJ foi fechado para manutenção, e uma das ações foi a substituição das instalações elétricas do edifício, na sua íntegra, devido a suas condições precárias.

No mapa de danos que apresenta as fissuras (figura 6), produzido em fevereiro e março de 2018, podemos notar uma grande concentração dessas manifestações patológicas junto aos vãos das portas, geralmente ocasionadas em decorrência da ausência, da má execução ou da degradação das vergas (sobre os vãos). Além disso, há grande concentração de fissuras nas paredes dos ambientes expositivos, derivadas, possivelmente, das vibrações e trepidações dos elementos com função estrutural (vedos), em razão da densidade urbana em que o SB está 
inserido atualmente, da dilatação e/ou da retração da taipa e do pau a pique conforme variações térmicas no decorrer do dia e das diferentes estações do ano ou também devido ao processo de restauro (argamassas e tintas inadequadas) das paredes do edifício, visto que as técnicas utilizadas - taipa e pau a pique - exigem que elementos estruturais (vedos autoportantes) sejam protegidos com revestimentos e pinturas orgânicas, compatíveis com a técnica construtiva.

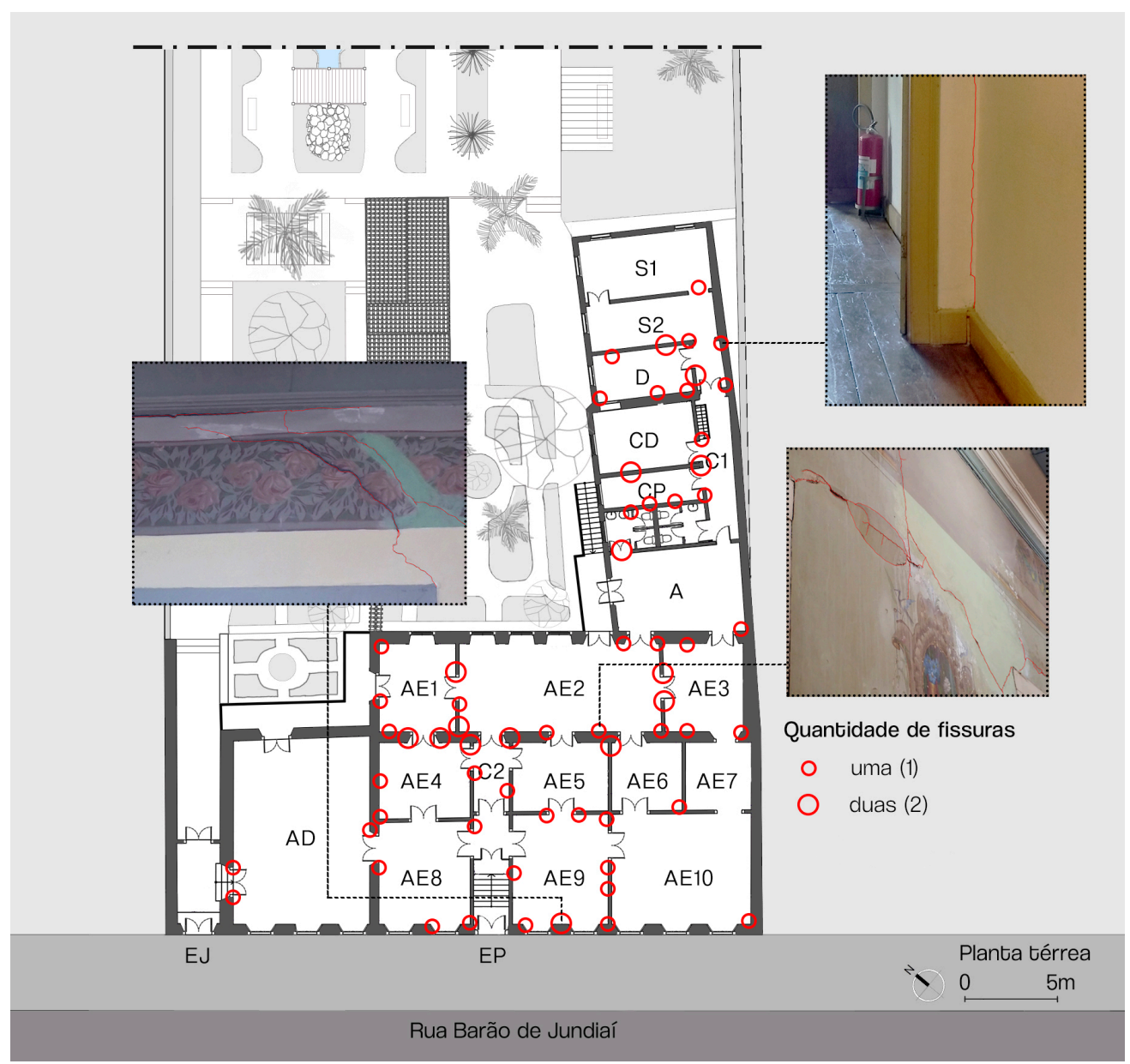

Figura 6 - Mapa de danos. Fissuras. Fonte: planta do piso térreo cedida pelo MHCJ, sem autoria identificada e adaptada e atualizada (usos dos ambientes internos e dos jardins e conferência in situ de medidas internas e dos jardins) pela pesquisadora, 2018 . Registros fotográficos realizados pela pesquisadora, 2018.

Obs.: Nas fotos as linhas vermelhas representam as fissuras em cada caso.

No mapa de danos que apresenta os descascados ou a ausência de tinta (figura 7), há dois casos particulares. A área expositiva 2 (AE 2) e a circulação (C) são 
os primeiros. Nesses dois ambientes, a pintura original da casa se mantinha, à época dos levantamentos realizados nesta pesquisa, preservada e, devido ao tempo, apresentava vários pontos descascados. Mesmo após reformas, esses ambientes não tiveram uma devida recuperação de suas pinturas. $\bigcirc$ outro caso particular envolvia a cozinha/área de descanso dos funcionários e a copa. Nesses dois ambientes foram observados pequenos pontos de descascados ou falta de tinta junto a áreas em que o azulejo descolou da parede. Nos outros ambientes havia pequenos pontos descascados ou falta de pintura devido à degradação do edifício, no decorrer de sua vida útil. Vale citar que se percebeu durante o levantamento de campo a constante preocupação da direção do museu em preservar o SB, especialmente seus aspectos formais e estéticos externos, repintando o edifício, interna e externamente, com regularidade.

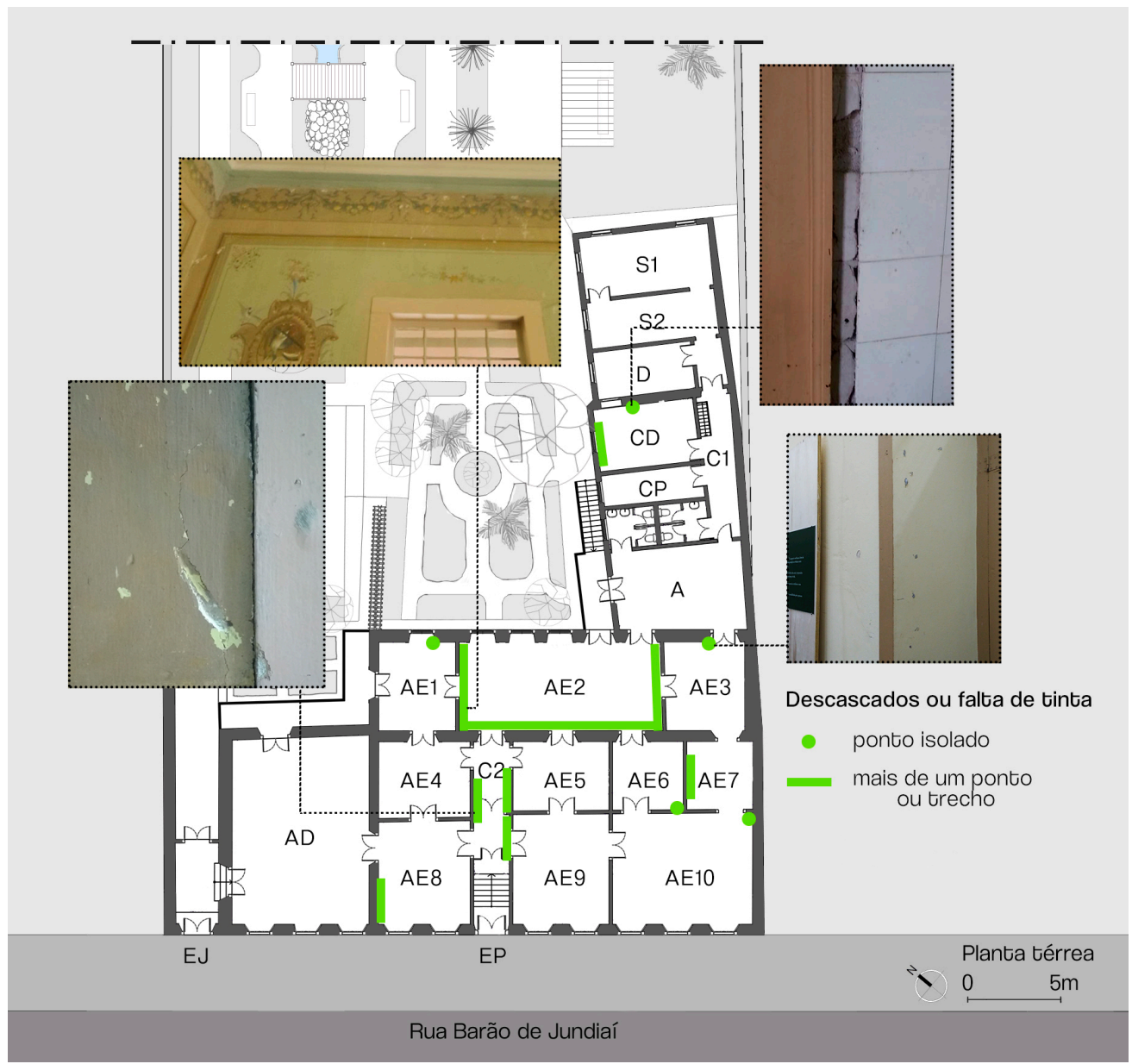

Figura 7 - Mapa de danos. Descascados ou falta de tinta. Fonte: planta do piso térreo cedida pelo $\mathrm{MHCJ}$, sem autoria identificada e adaptada e atualizada (usos dos ambientes internos e dos jardins e conferência in situ de medidas internas e dos jardins) pela pesquisadora, 2018. Registros fotográficos realizados pela pesquisadora, 2018. 
No mapa de danos que apresentava as infiltrações de águas de chuva (figura 8), foi possível verificar que há três tipos de infiltrações: apenas no forro, na junção do forro com o vedo e no piso ou rodapé. Quanto às infiltrações apenas no forro, havia indícios em dois pontos, sendo eles na AE 4 e na AE 9, nos vedos em contato com o lado externo do edifício. Quanto às infiltrações na junção do forro com a parede, havia indícios em quatro pontos, sendo dois deles na AE 1 e AE 10, em vedos em contato com o lado externo do edifício, o terceiro na AE 7, sala que apresentava abertura no forro estabelecendo contato direto com o telhado, e o quarto ponto estava na sala de serviços 2, que apresentava indício de infiltração provavelmente por algum problema como o deslocamento de telhas. Quanto às infiltrações no piso ou no rodapé, foram identificados alguns indícios na AE 10 e na AE 8. Na AE 10, os pontos de infiltração estão embaixo da esquadria (janela). Além disso, possivelmente devido à reforma do edifício ao lado do SB que contempla parede divisória comum (situação construtiva comum no século XIX e anteriores), a fachada frontal e principal do edifício SB sofreu movimentações e abaulamentos, especificamente nesse vedo em que se apresentam as infiltrações. Na AE 8, o indício de infiltração está na parede que este ambiente divide com o auditório.

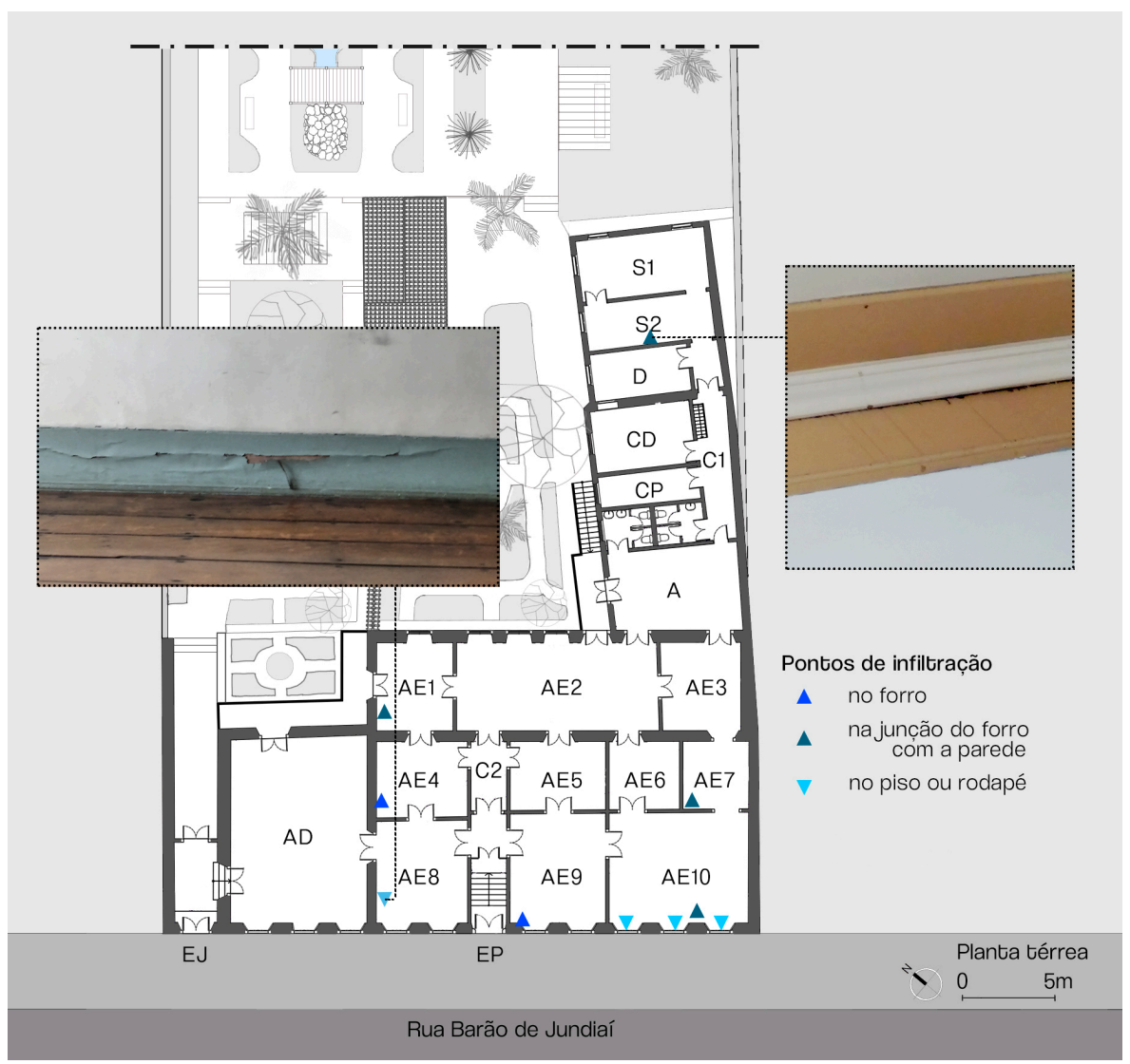

Figura 8 - Mapa de danos. Infiltrações. Fonte: planta do piso térreo cedida pelo $\mathrm{MHCJ}$, sem autoria identificada e adaptada e atualizada (usos dos ambientes internos e dos jardins e conferência in situ de medidas internas e dos jardins) pela pesquisadora, 2018. Registros fotográficos realizados pela pesquisadora, 2018. 
Apresentadas separadamente, ao sobrepor os três itens observados num mapa de danos geral (figura 9), foi possível observar que há dois eixos que necessitam de maior atenção devido ao acúmulo de fissuras, descascados ou falta de tinta e infiltrações de águas de chuva. $O$ primeiro deles é o eixo de parede de taipa de pilão que divide as áreas expositivas 1, 2 e 3 das áreas expositivas $4,5,6$ e 7 e da circulação. $O$ segundo eixo é o da fachada principal do edifício pelo lado interior, visto que no lado externo essas fissuras não são visíveis. Num segundo grau de atenção devem ser consideradas as portas e janelas (esquadrias) devido ao grande número de fissuras próximo a esses vãos, além de alguns pontos de infiltração igualmente próximos.

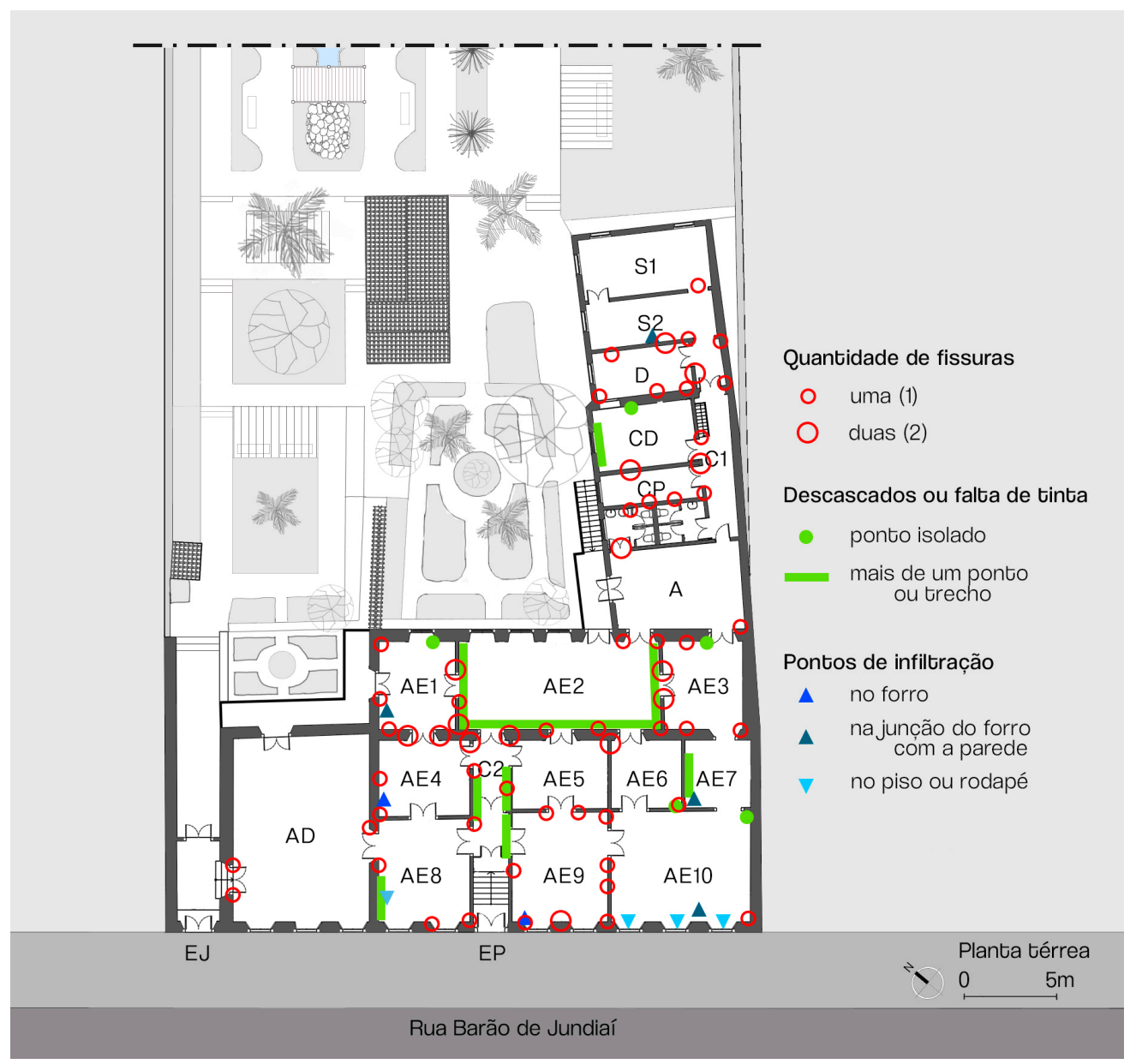

Figura 9 - Mapa de danos. Síntese. Fonte: planta do piso térreo cedida pelo $M H C J$, sem autoria identificada e adaptada e atualizada (usos dos ambientes internos e dos jardins e conferência in situ de medidas internas e dos jardins) pela pesquisadora, 2018. 
Embora, em geral, as fissuras do edifício aparentam ser superficiais, é necessário consultar especialistas para verificar a profundidade e as implicações técnicas dessas manifestações na conservação do conjunto edificado.

\section{PROCEDIMENTOS PARA A AVALIAÇÃO DE DESEMPENHO FÍSICO E PARA A AFERIÇÃO DA SATISFAÇÃO DOS USUÁRIOS}

A APO aplicada no SB, conforme já mencionado e seguindo essas premissas, foi dividida em avaliação de desempenho físico e na avaliação da satisfação dos usuários. Quanto à avaliação de desempenho físico, teve como base principal a NBR 15.575,36 que estabelece requisitos e critérios de desempenho para habitação a partir das exigências do usuário, mas esses critérios - universais - podem e devem ser adotados para outros tipos de edifícios e espaços abertos (por exemplo, museus e seus jardins) desde que adequados a estes edifícios e seus usos; a NBR 9.050,37 que estabelece parâmetros de acessibilidade; e as Instruções Técnicas do Corpo de Bombeiros de São Paulo ${ }^{38}$ que estabelecem as regras para segurança contra incêndio em edifícios.

Para realização da avaliação de desempenho físico foram elaborados mapas comportamentais dos usuários tanto internamente ao edifício quanto no jardim. Os mapas comportamentais são bases gráficas importantes para a compreensão e o planejamento dos espaços, especialmente museológicos, pois, o registro do comportamento dos usuários nesses espaços permite uma visualização geral dos locais onde há maior e menor concentração de pessoas e suas atividades, auxiliando no planejamento dos leiautes das exposições, das rotas acessíveis e de fuga, entre outros aspectos a serem considerados num programa de necessidades, base para um processo de projeto adequado. Além disso, foram elaborados três checklists, sendo um para o desempenho físico da edificação e suas possíveis manifestações patológicas, um para acessibilidade e um para a segurança contra incêndio e a segurança patrimonial. Com aspectos previamente estabelecidos a serem observados durante a avaliação, os checklists são instrumentos que buscam uma sequência lógica de observações que permitem uma avaliação mais completa dos aspectos técnicoconstrutivos, de segurança, funcionais e de acessibilidade dos ambientes. Como resultado dos checklists foram também elaborados mapas de danos, ${ }^{39}$ pontuando onde se encontram cada uma das manifestações patológicas verificadas.

Quanto à avaliação de satisfação dos usuários, foram realizadas seis entrevistas, sendo cinco individuais e uma em grupo, com pessoas-chave (tabela
36. Associação Brasileira de Normas Técnicas (2013a-f).

37. Associação Brasileira de Normas Técnicas (2015).

38. Corpo de Bombeiros... (2018).

39. Cf. Tinoco (2009) 
40. Cf. Souza (2019).

41. Escola de Artes, Ciências e Humanidades da Universidade de São Paulo.

42. Termo de Consentimento Livre e Esclarecido.
1) e aplicados cem questionários com visitantes adultos espontâneos, no período de maio a julho de 2018. Essa avaliação é importante, pois é o usuário que no dia a dia vivencia os aspectos da edificação, seus usos, os jardins e se relaciona com os diversos ambientes. ${ }^{40}$ Para a realização das entrevistas e a aplicação dos questionários foram elaborados roteiros que, junto com o projeto de pesquisa na sua íntegra, foram previamente submetidos e aprovados pela Comissão de Ética na Pesquisa (CEP) da EACH-USP41 através da Plataforma Brasil, sob número CAAE 820768 17.5.0000.5390. Além dos roteiros, para cada pessoa entrevistada e para cada questionário aplicado, foram assinados pelos entrevistados e pelos respondentes de questionários os respectivos TCLE. ${ }^{42}$

Tabela 1 . Entrevistas realizadas.

\begin{tabular}{|l|l|l|}
\hline \multicolumn{1}{|c|}{ Perfil dos entrevistados } & \multicolumn{1}{c|}{ Data } & \multicolumn{1}{c|}{ Entrevista } \\
\hline Funcionários da manutenção do edifício e áreas externas & 5 abr. 2018 & Em grupo \\
\hline Diretor & 12 abr. 2018 & Individual \\
\hline Educadora & 12 abr. 2018 & Individual \\
\hline Diretor do DPH & 26 abr. 2018 & Individual \\
\hline Representante da FAU/USP junto ao Condephaat & 14 jun. 2018 & Individual \\
\hline Técnica responsável da UPPH, Condephaat & 2 out. 2018 & Individual \\
\hline
\end{tabular}

Fonte: Elaboração própria, 2018.

Após coletados e processados, esses dados foram confrontados com os resultados obtidos da avaliação de desempenho físico do edifício, consolidando os diagnósticos "especialista versus usuários" para cada um dos itens avaliados do estudo de caso, de acordo com as respectivas normas e instruções técnicas.

\section{QUADROS SÍNTESE E MAPAS DE DIAGNÓSTICOS E RECOMENDAÇÕES}

Os quadros síntese e os mapas de diagnósticos e de recomendações são resultantes da APO e têm como objetivo a demonstração em planilhas e em bases gráficas dos principais resultados do cruzamento das informações da avaliação de desempenho físico do ambiente e a avaliação de satisfação dos usuários, identificando, sempre que possível, recomendações - base para soluções técnicas adequadas - à luz do quadro normativo e das instruções técnicas. A diferença 
entre os quadros síntese e os mapas de diagnósticos e de recomendações é a forma da apresentação da informação. Embora os dois sejam técnicos, o quadro é mais descritivo, os mapas são mais visuais. Ambos são instrumentos relevantes para a elaboração de um plano de ação por parte dos gestores do museu pois identificam e pontuam os aspectos positivos e aqueles a serem melhorados com base no risco que oferecem aos usuários, ao edifício (acervo imóvell e aos acervos móveis e estabelecem uma periodicidade recomendada para que as ações sejam realizadas, divididas em períodos de curto, médio e longo prazos.

Os quadros síntese e os mapas de diagnósticos e de recomendações aqui visualizados foram inspirados na matriz de descobertas apresentadas por Helena Rodrigues em seu Trabalho Final de Graduação (2002) com a colaboração de Isabelli Soares, então bolsistas do curso de graduação em Arquitetura e Urbanismo da Universidade Federal Fluminense. ${ }^{43}$

Na pesquisa em questão foi elaborado um quadro síntese com os cinco principais critérios de desempenho avaliados, a saber, acessibilidade, sistema construtivo, segurança contra incêndio, segurança patrimonial e sinalização. Dentro de cada um desses critérios foram abordados temas específicos, sendo que, para acessibilidade, foram elencadas questões de acesso, percurso, acessibilidade da exposição e banheiros; para o sistema construtivo foram abordadas as manifestações patológicas em todas as superfícies - pisos, vedos, forros e revestimentos; para segurança contra incêndio foram abordadas questões tanto de prevenção e identificação de incêndio, quanto contenção do fogo; para segurança patrimonial foi abordada a questão da vigilância por câmeras e por equipe especializada; e para sinalização foi abordada tanto a sinalização orientativa quanto a de emergência (rotas de fuga). Esses critérios foram avaliados com base nas normas e nas instruções técnicas, as quais são citadas junto ao item e, a partir disso, foram feitas as recomendações.

Os critérios avaliados, conforme já mencionado, foram classificados de acordo com o nível de risco que oferece ao usuário e à conservação do patrimônio (bens imóveis e móveis) em quatro categorias: mínimo, baixo, médio e elevado. De modo que o risco mínimo se refere a critérios como, por exemplo, a acessibilidade das exposições, que não apresenta riscos (ou apresenta eventuais riscos mínimos), mas podem ser melhorados. Risco baixo refere-se a critérios como as manifestações patológicas nos revestimentos, dentre outros, que aparentemente apresentam risco baixo aos usuários, mas sem a devida atenção podem vir a apresentar riscos maiores. Risco médio refere-se a critérios como, por exemplo, as manifestações patológicas nas paredes (fissuras), que embora aparentam ser superficiais, precisam de atenção e monitoramento para verificar se há aumento crescente das fissuras no decorrer do
43. Rheingantz et al. (2009, p.91), sendo a primeira referência à matriz constante de Rodrigues; Castro; Rheingantz (2004) e Assoni; Ornstein (2019). 
tempo, podendo indicar riscos maiores. Por fim, o risco elevado refere-se a critérios como a necessidade de modernização e da substituição da fiação e dos quadros de energia elétrica do edifício, dentre outros, pois estes aspectos da infraestrutura e das instalações podem implicar em riscos elevados aos usuários e ao patrimônio, inclusive em termos de segurança contra incêndio.

Além disso, foi estabelecido um prazo recomendado para que as intervenções sejam feitas. $\bigcirc$ prazo é dividido em três categorias, sendo curto prazo referente às intervenções que, em geral, oferecem maior risco aos usuários e ao patrimônio e deveriam ser realizadas num prazo máximo de até seis meses; médio prazo referente às intervenções que, em geral, oferecem um risco menor aos usuários e ao patrimônio e deveriam ser realizadas num prazo entre seis e 12 meses; longo prazo referente às intervenções que, em geral, oferecem risco mínimo aos usuários e ao patrimônio e, por esta razão, poderiam ser executados num prazo entre 12 e 24 meses.

Para exemplificar como foram inseridas as informações no quadro síntese, apresentamos, a seguir, o caso do acesso ao museu, para o do tema da Acessibilidade (tabela 2), assim como os mapas de diagnósticos e de recomendações.

Tabela 2. Acessibilidade. Exemplo de trecho do quadro síntese.

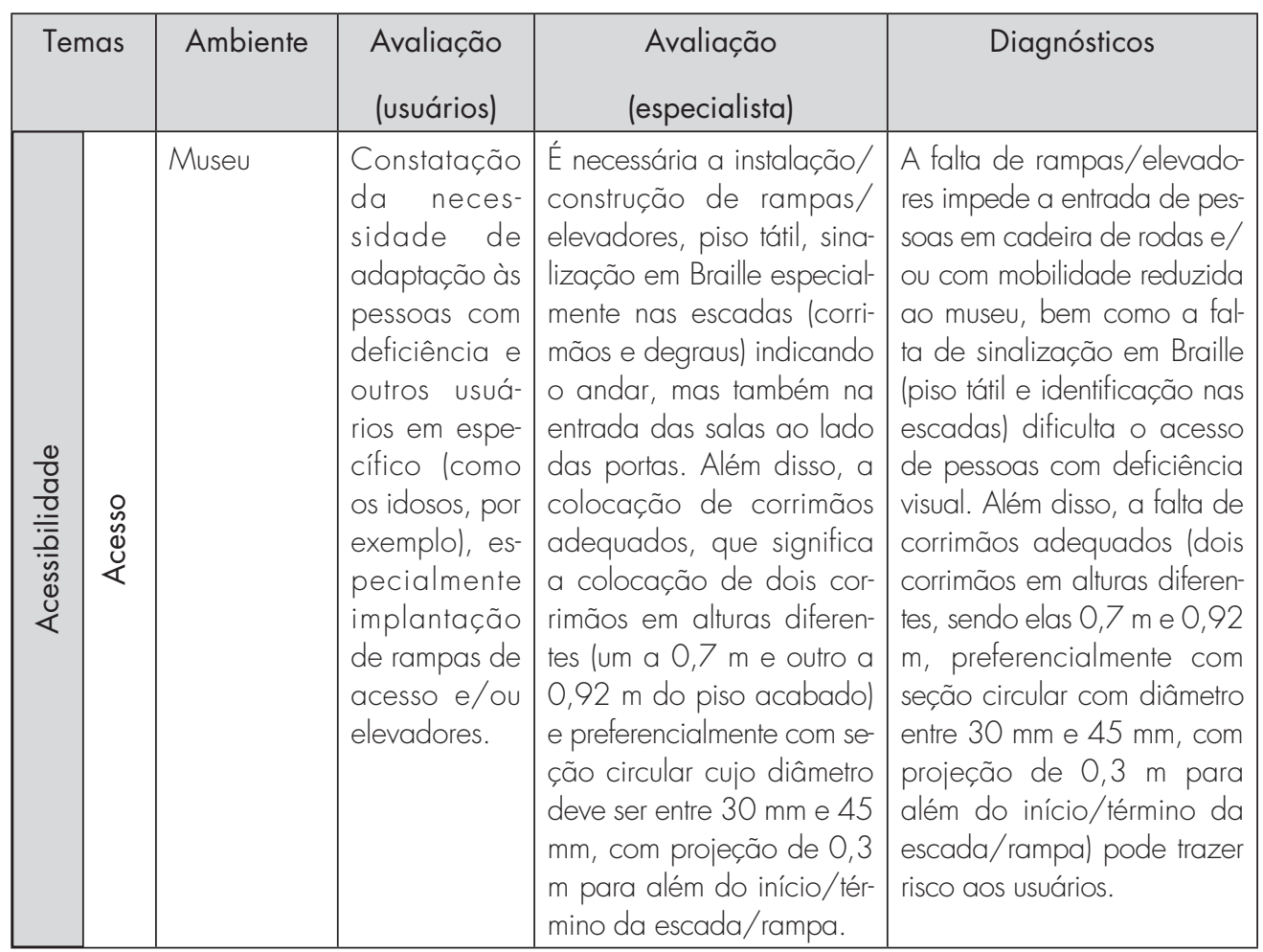




\begin{tabular}{|c|c|c|c|}
\hline $\begin{array}{c}\text { Normas } \\
\text { associadas }\end{array}$ & Recomendações & $\begin{array}{l}\text { Nível de risco } \\
\text { (elevado, médio, } \\
\text { baixo, mínimo) }\end{array}$ & $\begin{array}{c}\text { Prazo } \\
\text { (curto, médio } \\
\text { ou longo) }\end{array}$ \\
\hline $\begin{array}{l}\text { NBR } 9.050^{44}, \\
\text { NBR } 16.537^{45}, \\
\text { Caderno de } \\
\text { Acessibilidade } \\
\text { a Museus }\end{array}$ & $\begin{array}{l}\text { Instalação de elevador no jardim dando } \\
\text { acesso ao museu pela varanda do audi- } \\
\text { tório de modo a não danificar/modificar } \\
\text { a estrutura do edifício. Instalação de piso } \\
\text { tátil e sinalização de acesso em Braille } \\
\text { especialmente nas escadas (corrimãos e } \\
\text { degraus) indicando o andar, mas também } \\
\text { na entrada das salas ao lado das portas } \\
\text { e onde mais necessário for. Instalação } \\
\text { de corrimãos adequados em duas alturas } \\
\text { (um a } 0,7 \text { m e outro a } 0,92 \text { m do piso } \\
\text { acabado) e preferencialmente com seção } \\
\text { circular cujo diâmetro deve ser entre } 30 \\
\text { mm e } 45 \text { mm, com projeção de } 0,3 \text { m } \\
\text { para além do início/término da escada/ } \\
\text { rampa, conforme previsto na norma. }\end{array}$ & Elevado & Curto \\
\hline
\end{tabular}

44. Associação Brasileira de Normas Técnicas (2015).

45. Id., 2018.

46. IBRAM, 2012.

Os mapas de diagnósticos e de recomendações foram feitos com base nos critérios já elencados, porém, num formato com vistas à visualização expedita pelos tomadores de decisão. Foram elaborados quatro mapas, sendo um deles específico para os critérios de acessibilidade (figuras 10 a, b, c), um para os critérios de sistema construtivo (figuras $11 a, b, c, d$ ), um para os critérios de segurança contra incêndio (figuras 12 a, b) e um último para os critérios de segurança patrimonial e sinalização (figura 13).

Neste estudo exploratório de APO, os mapas de diagnósticos e de recomendações oferecem um registro temporal das condições físicas do $\mathrm{MHCJ}$ e da percepção e satisfação dos seus visitantes. A visualização dos documentos anteriormente apresentados permite auxiliar os tomadores de decisão quanto às boas práticas prioritárias a serem implementadas na direção da preservação e da conservação desse bem patrimoniado e relevante local e regionalmente. Observouse - para aquele determinado período de avaliação - a necessidade de implementar as ações de readequação das instalações elétricas, de segurança contra incêndio e de acessibilidade, estas duas últimas não só implementadas no interior do edifício, mas também de forma integrada com os jardins, tendo-se em mente os usuários com deficiência e o acesso eventual, mas de risco de equipes do corpo de bombeiros com seus equipamentos, além da proximidade de veículos específicos para auxílio no combate ao fogo. 
Figura 1Oa - Mapa de diagnósticos e recomendações de acessibilidade. Fonte: planta do piso térreo cedida pelo $M H C J$, sem autoria identificada e adaptada e atualizada (usos dos ambientes internos e dos jardins e conferência in situ de medidas internas e dos jardins) pela pesquisadora, 2018

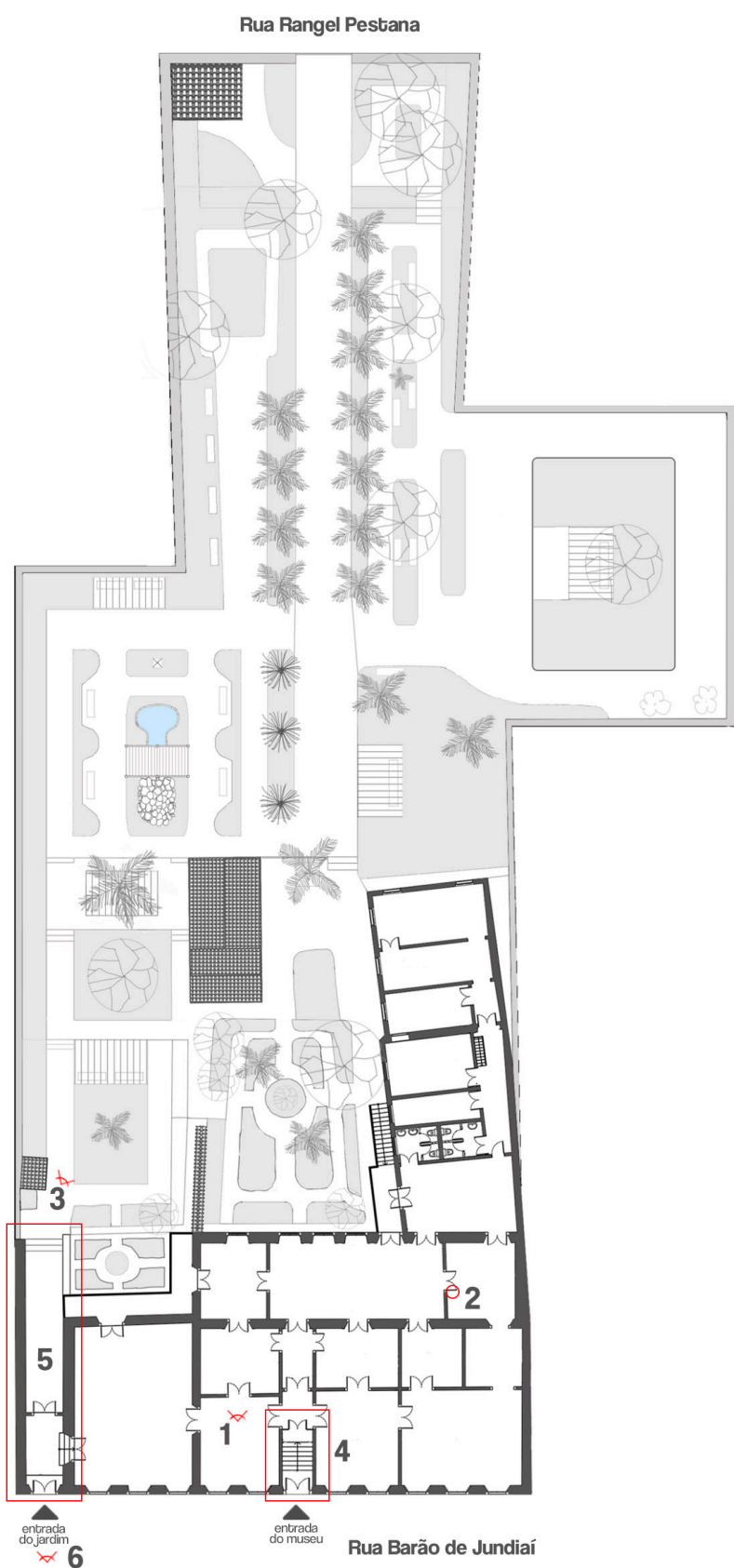

Mapa de Diagnóstico e Recomendações MHCJ - Solar do Barão

in acessibililade

IIII sinalização

Sh sistema construtivo

segurança contra incêndio

- segurança patrimonial
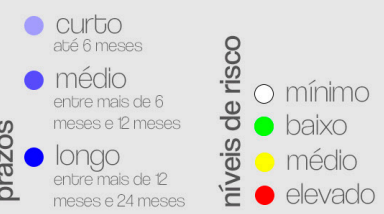

FAUUSP • FAPESP Bolsista IC: Raissa Melo de Souza Orientadora: Sheila Walbe Ornstein

Planta. diagnósticos e recomendacões referente ao período de fevereiro a julho de 2018 


\begin{tabular}{l}
\hline Percurso no Museu \\
Diagnóstico \\
Necessidade de instalação de piso tátil e \\
sinalização em Braille dos acessos das \\
salas e de localização no interior do \\
museu. Necessidade de verificação de \\
todo o piso e recuperação dos trechos \\
que apresentam vãos com mais de 15mm \\
(máximo aceitável pela NBR 9050) devido \\
a desgastes naturais do tempo e/ou \\
faltta de manutenção preventiva. \\
Recomendações \\
Instalar piso tátil e sinalização em Braille \\
os acessos das salas e de localização no \\
interior do museu. Verificar todo o piso e \\
recuperar trechos que apresentam vãos \\
com mais de 15mm (máximo aceitável \\
pela NBR 9050) devido a desgastes \\
naturais do tempo e/ou falta de ma- \\
nutenção preventiva. \\
Normas Associadas \\
NBR 5674 (ABNT, 2012), NBR 9050 (ABNT, \\
2015), NBR 15575 (ABNT, 2013), NBR 16280 \\
(ABNT, 2015), Caderno de Acessibilidade \\
a Museus (IBRAM, 2012).
\end{tabular}
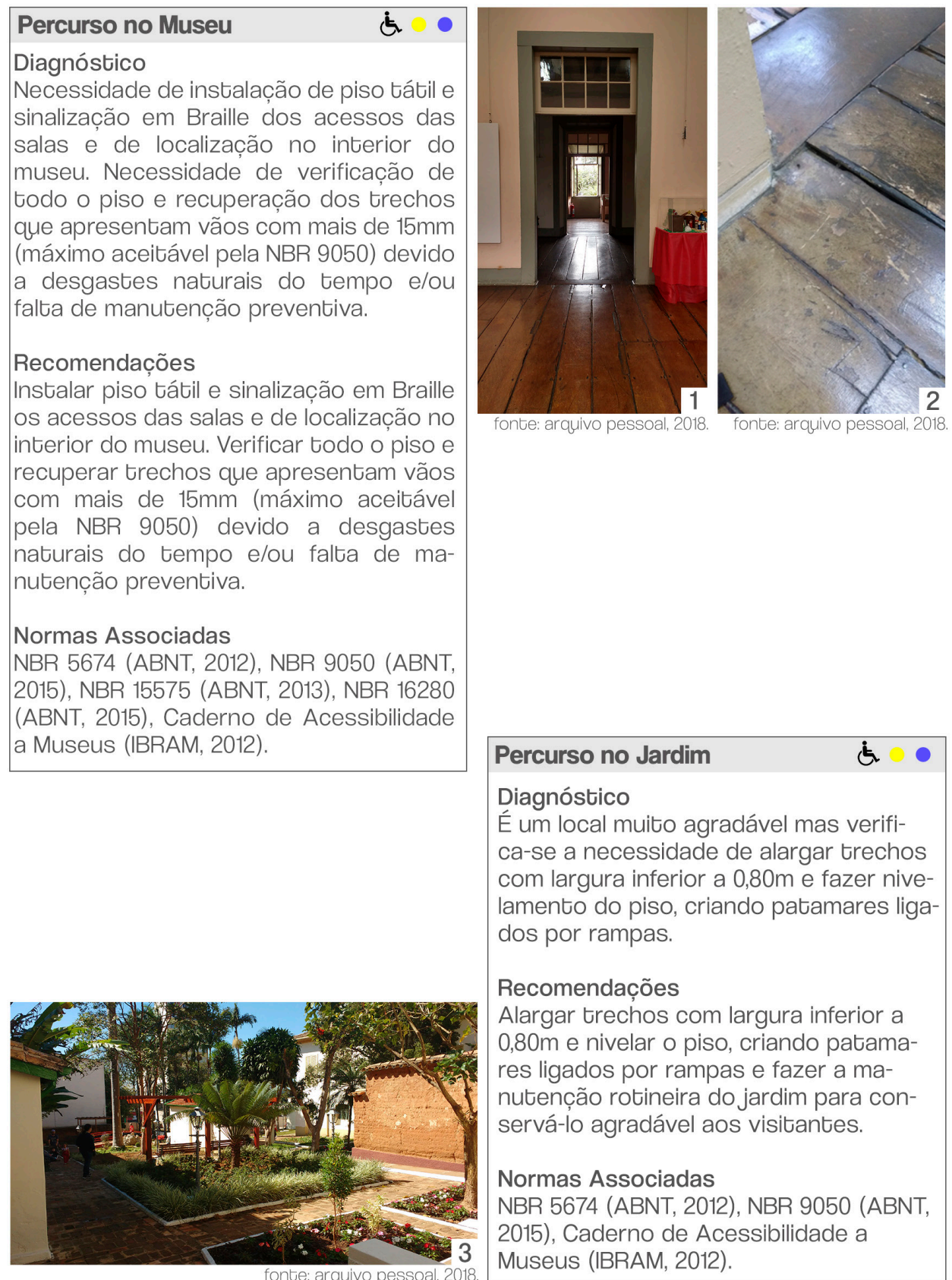

\begin{tabular}{l}
\hline Percurso no Jardim \\
Diagnóstico \\
É um local muito agradável mas verifi- \\
ca-se a necessidade de alargar trechos \\
com largura inferior a 0,80m e fazer nive- \\
lamento do piso, criando patamares liga- \\
dos por rampas. \\
Recomendações \\
Alargar trechos com largura inferior a \\
0,80m e nivelar o piso, criando patama- \\
res ligados por rampas e fazer a ma- \\
nutenção rotineira do jardim para con- \\
servá-lo agradável aos visitantes. \\
Normas Associadas \\
NBR 5674 (ABNT, 2012), NBR 9050 (ABNT, \\
2015), Caderno de Acessibilidade a \\
Museus (IBRAM, 2012).
\end{tabular}

Mapa de Diagnóstico e Recomendações MHCJ - Solar do Barão
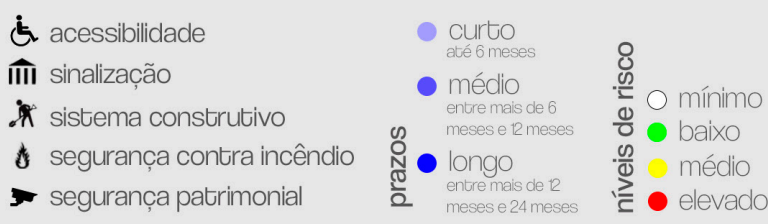

FAUUSP • FAPESP Bolsista IC: Raissa Melo de Souza Orientadora: Sheila Walbe Ornstein

Planta. diagnósticos e recomendacões referente ao período de fevereiro a julho de 2018
Figura 1Ob - Mapa de diagnósticos e recomendações de acessibilidade. Fonte: elaborado pela pesquisadora, 2018. Registros fotográficos realizados pela pesquisadora, 2018. 


\begin{tabular}{|l|}
\hline Acesso ao Museu \\
Diagnóstico \\
É necessária a instalação/construção de \\
rampas/elevadores, piso tátil, sinalização \\
em Braille especialmente nas escadas \\
(corrimãos e degraus) indicando o andar, \\
mas também na entrada das salas ao \\
lado das portas. Além disso, a colocação \\
de corrimãos adequados, que significa a \\
colocação de dois corrimãos em alturas \\
diferentes (um a 0,7m e outro a 0,92m do \\
piso acabado) e preferencialmente com \\
seção circular cujo diâmetro deve ser \\
entre 30 e 45mm, com projeção de 0,3m \\
para além do início/término da es- \\
cada/rampa. \\
Recomendaçães \\
Instalação de elevador no jardim dando \\
acesso ao museu pela varanda do au- \\
ditório de modo a não danificar/modificar \\
a estrutura do edifício. Instalação de \\
piso tátil e sinalização de acesso em \\
Braille especialmente nas escadas (cor- \\
rimãos e degraus) indicando o andar, \\
mas também na entrada das salas ao \\
lado das portas e onde mais necessário \\
for. \\
Instalaccão de corrimãos adequados em \\
duas altturas (um a 0,7m e outro a 0,92m \\
do piso acabado) e preferencialmente \\
com seção circular cujo diâmetro deve \\
ser entre 30 e 45mm, com projeção de \\
0,3m para além do início/término da es- \\
cada/rampa, conforme previsto na \\
norma. \\
Normas Associadas \\
NBR 9050 (ABNT, 2015), NBR16537 (ABNT, \\
2018 ), Caderno de Acessibilidade a \\
Museus (IBRAM, 2012). \\
\hline
\end{tabular}

\section{Acesso ao jardim \\ 5 ㄴ. \\ Diagnóstico \\ Necessidade de instalação/construção de uma rampa até o patamar central e redução de pequenos desníveis, tendo como base esse patamar central.}

\section{Recomendações}

Instalação/Construção de rampa até o patamar central e redução/nivelamento dos desníveis a partir desse patamar possibilitando acesso geral ao jardim.

\section{Normas Associadas}

NBR 9050 (ABNT, 2015), Caderno de Acessibilidade a Museus (IBRAM, 2012).

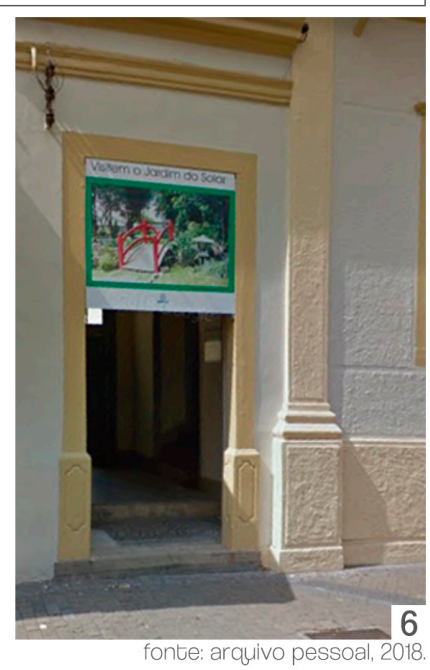

Figura 10c - Mapa de diagnósticos e recomendações de acessibilidade. Fonte: elaborado pela pesquisadora, 2018. Registro fotográfico realizado pela pesquisadora, 2018.

\section{Mapa de Diagnóstico e Recomendações MHCJ - Solar do Barão}

in acessibililade

IIII sinalização

sistema construtivo

segurança contra incêndio

- segurança patrimonial

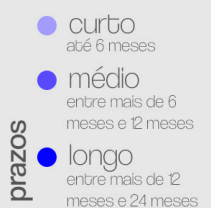

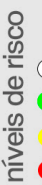

FAUUSP • FAPESP Bolsista IC: Raissa Melo de Souza Orientadora: Sheila Walbe Ornstein

Planta, diagnósticos e recomendacões alanta, diagnósticos e recomendaç̃os 


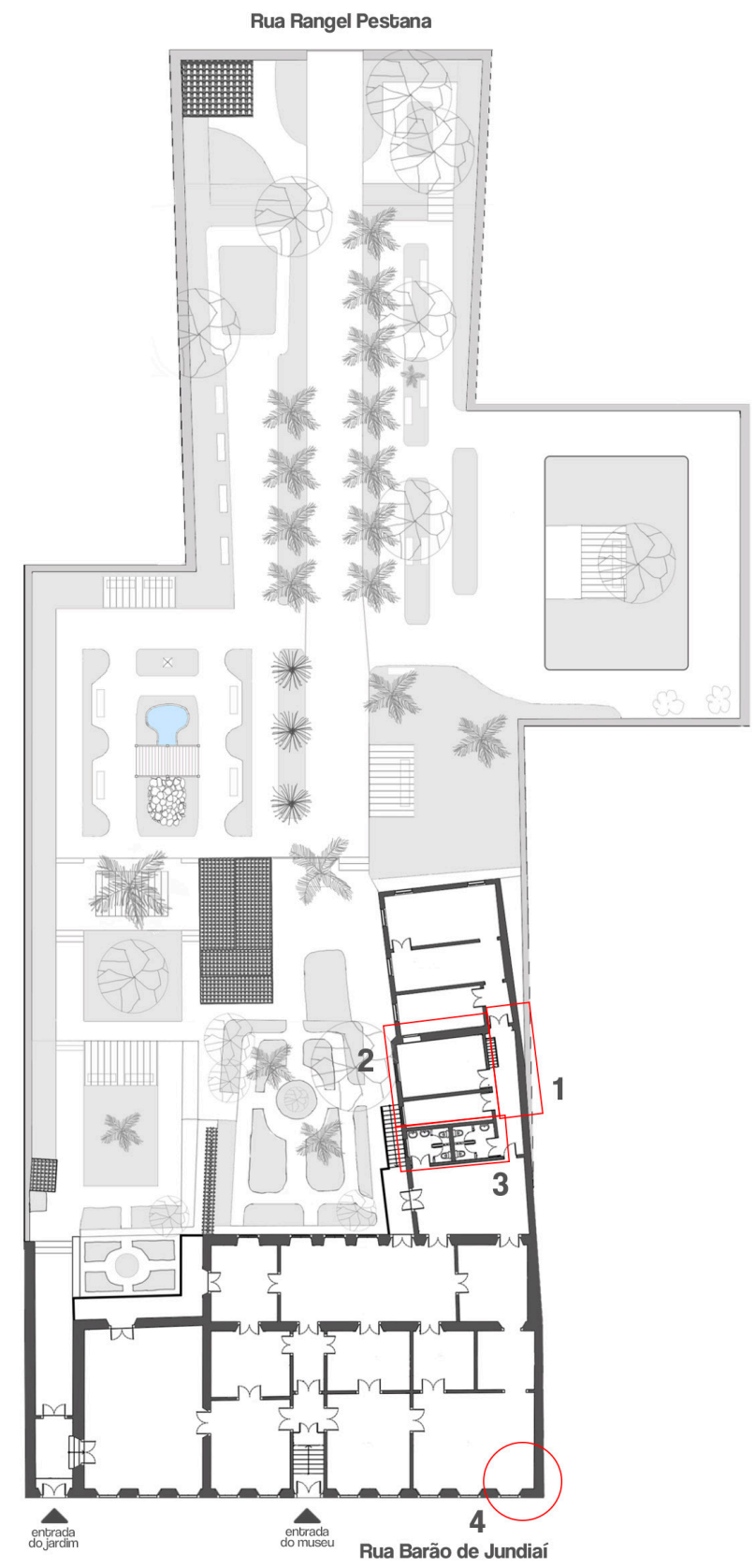

\section{Mapa de Diagnóstico e Recomendações MHCJ - Solar do Barão}

i. acessibilidade

IIII sinalização

- sistema construtivo

¿ segurança contra incêndio

- segurança patrimonial

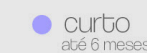

médio

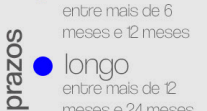
$\stackrel{\substack{\text { Planta Pav. Principal } \\ \hdashline}}{\longrightarrow}$
FAUUSP • FAPESP Bolsista IC: Raissa Melo de Souza Orientadora: Sheila Walbe Ornstein

Planta, diagnósticos e recomendacões referente ao período de fevereiro a julho de 2018
Figura 11 la - Mapa de diagnósticos e recomendações de sistema construtivo. Fonte: planta do piso térreo cedida pelo $\mathrm{MHCl}$, sem autoria identificada e adaptada e atualizada lusos dos ambientes internos e dos jardins e conferência in situ de medidas internas e dos jardins) pela pesquisadora, 2018. 


\begin{tabular}{|l|}
\hline Áreas de Apoio \\
Diagnóstico \\
Necessidade de reposição do piso e veri- \\
ficação do motivo da instabilidade. Cor- \\
reção das fissuras nas paredes. \\
Recomendações \\
Fazer uma avaliação para verificar a pro- \\
fundidade e o impacto das fissuras na \\
estrutura das paredes. Fazer uma aval- \\
iação e verificar a profundidade dos \\
danos no piso e o motivo de sua instabil- \\
idade, substituindo as partes \\
necessárias e consertando os devidos \\
problemas. \\
Normas Associadas \\
NBR 15575 (ABNT, 2013).
\end{tabular}

Fachada
Diagnóstico
Necessidade de manutenção corretiva
na fachada e no telhado.
Recomendações
Fazer uma avaliação do impacto cau-
sado nos elementos estruturais da
fachada e a manutenção corretiva
tanto da fachada quanto do telhado.
Normas Associadas
NBR 5674 (ABNT, 2012), NBR 15575(ABNT,
2013), NBR 16280 (ABNT, 2015).

Áreas de Apoio Molháveis - Copa e Cozinha

$2 \cdot x$

\section{Diagnóstico}

Necessidade de reposição dos azulejos que destacaram e manutenção/recuperação do piso desgastado.

\section{Recomendações}

Fazer uma avaliação para verificar a causa do destacamento, corrigir as possíveis falhas e repor azulejos. Fazer a manutenção/recuperação do piso degradado.

Normas Associadas

NBR 5674 (ABNT, 2012), NBR 15575 (ABNT, 2013), NBR 16280 (ABNT, 2015).

\section{Áreas de Apoio Molhadas - Banheiros}

3.

\section{Diagnóstico}

Banheiros em bom estado de conservação. É necessário adaptar o banheiro com barras de apoio, louças adequadas, bem como os itens básicos do banheiro como papeleira, espelho, etc. Todas as medidas estão especificadas na norma de acessibilidade NBR 9050 (ABNT, 2015) de forma clara e direta.

\section{Recomendações}

Fazer manutenção rotineira e preventiva. Fazer a adaptação do banheiro com barras de apoio, louças adequadas, bem como os itens básicos do banheiro como papeleira, espelho, etc. Todas as medidas estão especificadas na norma de acessibilidade NBR 9050 (ABNT, 2015) de forma clara e direta.

Normas Associadas

NBR 5674 (ABNT, 2012), NBR 15575 (ABNT, 2013), NBR 16280 (ABNT, 2015).

Figura $11 b-$ Mapa de diagnósticos e recomendações de sistema construtivo. Fonte: elaboração própria, 2018.

\section{Mapa de Diagnóstico e Recomendações MHCJ - Solar do Barão}
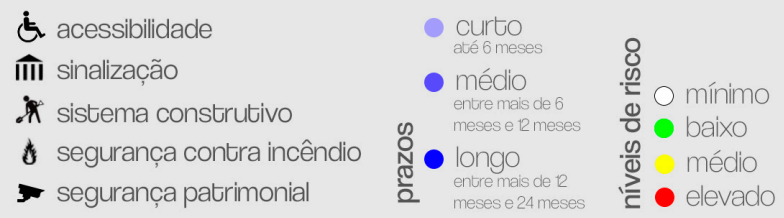

FAUUSP • FAPESP Bolsista IC: Raissa Melo de Souza Orientadora: Sheila Walbe Ornstein

Planta. diagnósticos e recomendacões referente ao período de fevereiro a julho de 2018 


\section{Instalações Elétricas}

Diagnóstico

Necessita da troca da fiação elétrica (desde quadros de distribuição até as tomadas e interruptores) e devido encapamento dos fios, mantendo longe dos usuários. Também é necessária a identificação da voltagem das tomadas.

\section{Recomendações}

Fazer a troca da fiação elétrica (desde quadros de distribuição até as tomadas e interruptores) bem como o devido encapamento dos fios, mantendo longe dos usuários. Fazer a devida identificação da voltagem das tomadas.

Normas Associadas

NBR 5410 (ABNT, 2004), NBR 9050 (ABNT, 2015), NBR 15575 (ABNT, 2013), Caderno de Segurança em Museus (IBRAM, 2011).

\section{Forros}

\section{Diagnóstico}

É necessário corrigir as fissuras e identificar se os pontos de infiltração de águas de chuva estão danificando a estrutura em algum grau.

\section{Recomendações}

Fazer uma avaliação criteriosa sobre a profundidade e o impacto das fissuras e infiltrações para então tomar as devidas providências em relação a cada uma delas com vistas a correção e manutenção da integridade do edifício.

\section{Normas Associadas}

NBR 5674 (ABNT, 2012), NBR 9050 (ABNT, 2015), NBR 15575 (ABNT, 2013), NBR 16280 (ABNT, 2015), Caderno de Segurança em Museus (IBRAM, 2011).

Vedos
Diagnóstico
É necessário fazer uma avaliação criteriosa sobre a profundidade e o impacto das fis-
suras com relação às condições físicas do edifício em geral para então tomar as dev-
idas providências em relação a cada uma delas com vistas a correção e manutenção
da integridade do edifício.
Recomendações
Fazer uma avaliação criteriosa sobre a profundidade e o impacto das fissuras
para então tomar as devidas providências em relação a cada uma delas com vistas
a correção e manutenção da integridade do edifício.
Normas Associadas
NBR 5674 (ABNT, 2012), NBR 15575 (ABNT, 2013), NBR 16280 (ABNT, 2015), Caderno de
Segurança em Museus (IBRAM, 2011).

\section{Mapa de Diagnóstico e Recomendações MHCJ - Solar do Barão}

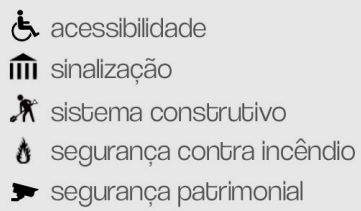

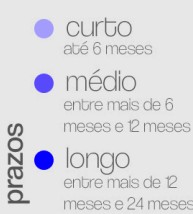

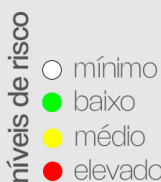

FAUUSP • FAPESP Bolsista IC: Raissa Melo de Souza Orientadora: Sheila Walbe Ornstein

Planta. diagnósticos e recomendacões referente ao período de fevereiro a julho de 2018
Figura 1 1c - Mapa de diagnósticos e recomendações de sistema construtivo. Fonte: elaboração própria, 2018. 


\section{Revestimentos}

Diagnóstico

É necessário verificar o motivo do descascamento e, sendo apenas desgaste natural, corrigir com a tinta adequada, preservando as características da pintura original e a ventilação dos vedos, pois estruturas de taipa precisam de troca de ar com o ambiente para permanecerem estabilizadas.

\section{Recomendações}

Fazer verificação do motivo do descascamento e, sendo apenas desgaste natural, corrigir com a tinta adequada, preservando as características da pintura original e a ventilação dos vedos, pois estruturas de taipa precisam de troca de ar com o ambiente para permanecerem estáveis.

Normas Associadas

NBR 15575 (ABNT, 2013), Caderno de Segurança em Museus (IBRAM, 2011).

\section{Áreas Expositivas}

\section{Diagnóstico}

É necessária a adaptação dos textos e dos itens expostos para recepcionar os possíveis visitantes que apresentem deficiência visual ou mesmo usuários não alfabetizados ou com dificuldade de leitura.

\section{Recomendaç̃es}

Fazer a adaptação dos textos e dos itens expostos, apresentando a opção da leitura em Braille bem como a opção de áudio-guia para usuários com baixa ou nenhuma visão e também usuários não alfabetizados ou com dificuldade de leitura.

\section{Normas Associadas}

NBR 9050 (ABNT, 2015), Caderno de Acessibilidade a Museus (IBRAM, 2012).

Pisos
Diagnóstico
É preciso fazer a reposição de tábuas danificadas e realizar verificação da amplitude
dos danos na estrutura em madeira de suporte do piso.
Recomendações
Fazer levantamento rigoroso (tábua a tábua) para identificar os trechos mais danifi-
cados e substituí-los, verificando, inclusive, se há danos estruturais mais graves nas
estruturas inferiores, possíveis de serem acessadas através dos porões do museu.
Normas Associadas
NBR 5674 (ABNT, 2012), NBR 9050 (ABNT, 2015), NBR 15575 (ABNT, 2013), NBR 16280
(ABNT, 2015), Caderno de Segurança em Museus (IBRAM, 2011).

Figura $11 d-M a p a$ de diagnósticos e recomendações de sistema construtivo. Fonte: elaboração própria, 2018.

\section{Mapa de Diagnóstico e Recomendações MHCJ - Solar do Barão}

in acessibililade

IIII sinalização

xistema construtivo

to segurança contra incêndio

- segurança patrimonial

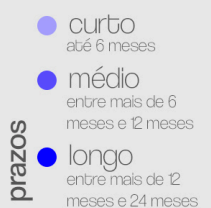

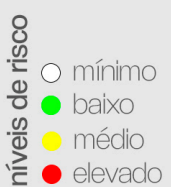

FAUUSP • FAPESP Bolsista IC: Raissa Melo de Souza Orientadora: Sheila Walbe Ornstein

Planta, diagnósticos e recomendaç̃es referente ao período de fevereiro a julho de 2018 


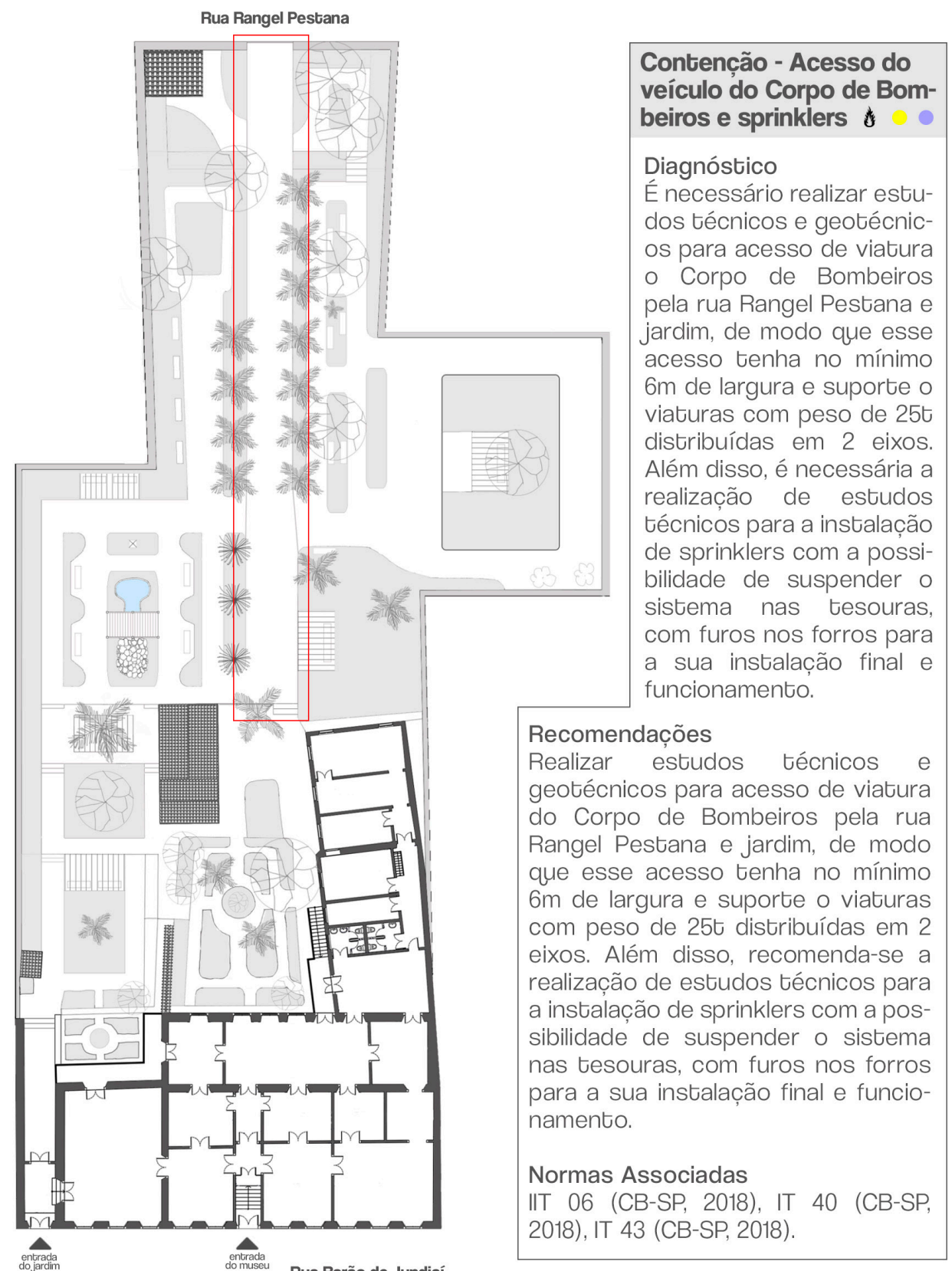

Mapa de Diagnóstico e Recomendações MHCJ - Solar do Barão

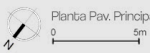

i. acessibilidade

IIII sinalização

. sistema construtivo

segurança contra incêndio

- segurança patrimonial
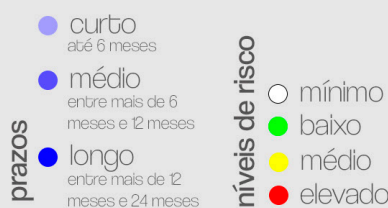

FAUUSP • FAPESP Bolsista IC: Raissa Melo de Souza Orientadora: Sheila Walbe Ornstein

Planta. diagnósticos e recomendacões referente ao período de fevereiro a julho de 2018
Figura 12a - Mapa de diagnósticos e recomendações de segurança contra incêndio. Fonte: planta do piso térreo cedida pelo $\mathrm{MHCJ}$, sem autoria identificada e adaptada e atualizada lusos dos ambientes internos e dos jardins e conferência in situ de medidas internas e dos jardins) pela pesquisadora, 2018. 


\begin{tabular}{|l|}
\hline Prevenção \\
Diagnóstico \\
É necessário treinar (anualmente) e identificar os \\
três brigadistas obrigatórios do museu. \\
Recomendações \\
Dar treinamento anualmente e identificar os três \\
brigadistas obrigatórios do museu. \\
Normas Associadas \\
IT 17 (CB-SP, 2018), IT 40 (CB-SP, 2018), IT 43 (CB-SP, \\
2018).
\end{tabular}

\section{Identificação}

$\Delta$

Diagnóstico

É necessário instalar uma central de deteccão de incêndio e um alarme geral da edificação. A central deve ser instalada em local com constante vigilância humana e de fácil visualização e deve estar ligada ao alarme geral que, caso acionado, seja audível em toda a área do museu, tanto para ações de contenção quanto

para evacuação do edifício.

\section{Recomendações}

Instalar central de deteccão de incêndio e alarme geral da edificação. A central deve ser instalada em local com constante vigilância humana e de fácil visualização e deve estar ligada ao alarme geral que, caso acionado, seja audível em toda a área do museu, tanto para ações de contenção quanto para evacuação do edifício

Normas Associadas

IT 19 (CB-SP, 2018), IT 40 (CB-SP, 2018), IT 43 (CB-SP, 2018).

\section{Contenção - PCF e barra anti-pânico}

\section{Diagnóstico}

É necessária a instalação de portas com abertura no sentido da rota de fuga com barras anti-pânico e instalação de portas corta fogo à prova de fumaça.

\section{Recomendações}

É recomendado instalar porta corta-fogo à prova de fumaça no acesso às áreas administrativas (por ser o único local onde esta pode permanecer fechada, como recomenda a NBR 11742, e por ser uma área intermediária do edifício para fazer a compartimentação horizontal).

\section{Contenção - Hidrante}

\section{Diagnóstico}

É necessária a instalação de hidrante e reservatório de água (estimado em 40 mil litros) para a contenção mais rápida possível de incêndios. Além disso, embora os extintores estejam bem situados, conforme a instrução técnica, é necessário mantê-los dentro do prazo de validade, bem sinalizados e o acesso desobstruído em todas as situações.

\section{Recomendações}

Instalar hidrante e reservatório de água (estimado em 40 mil litros), garantindo a estanqueidade deste. Além disso, embora os extintores estejam bem situados, conforme a instrucão técnica, recomenda-se mantê-los dentro do prazo de validade, bem sinalizados e com o acesso desobstruído em todas as situações.

Normas Associadas

IT 21 (CB-SP, 2018), IT 22 (CB-SP, 2018), IT 40 (CB-SP, 2018), IT 43 (CB-SP, 2018).

\section{Contenção - Saídas de Emergência}

\section{Diagnóstico}

É necessária a sinalização das saídas de emergência e das rotas de fuga em todo o museu, especificamente no bloco de apoio, cujo caminhamento até a rota de fuga é o mais longo da edificação (embora ainda esteja dentro dos $30 \mathrm{~m}$ máximos para que não seja necessária a construção de outra saída).

\section{Recomendações}

É recomendado instalar sinalização nas saídas de emergência e nas rotas de fuga em todo o museu, especificamente no bloco de apoio, cujo caminhamento até a rota de fuga é o mais longo da edificacão (embora ainda esteja dentro dos 30m máximos para que não seja necessária a construção de outra saída).

Normas Associadas

IT 11 (CB-SP, 2018), IT 20 (CB-SP, 2018), IT 40 (CB-SP, 2018), IT 43 (CB-SP, 2018)

Além disso, recomenda-se a instalação portas com abertura no sentido da rota de fuga com barras anți-pânico.

Normas Associadas

NBR 11742 (ABNT, 2018), NBR 11785 (ABNT, 2018).
Figura $12 b-$ Mapa de diagnósticos e recomendações de segurança contra incêndio. Fonte: elaboração própria, 2018.

\section{Mapa de Diagnóstico e Recomendações MHCJ - Solar do Barão}

in acessibilidade

IIII sinalização

xistema construtivo

segurança contra incêndio

- segurança patrimonial

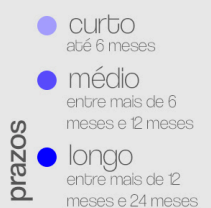

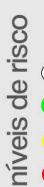

FAUUSP • FAPESP Bolsista IC: Raissa Melo de Souza Orientadora: Sheila Walbe Ornstein

Planta, diagnósticos e recomendaç̃es médio

médio

elevado 


\section{Vigilância - Áreas Expositivas e Porões}

\section{Diagnóstico}

É necessário realizar a troca de fiação elétrica e fazer a modernização do sistema de vigilância por câmeras.

\section{Recomendações}

Realizar a troca de fiação elétrica e fazer a modernização do sistema de vigilância por câmeras.

\section{Normas Associadas}

Caderno de Segurança em Museus (IBRAM, 2011).

\begin{tabular}{|l}
\hline Sinalização Orientativa \\
Diagnóstico \\
Necessidade de sinalização orientativa \\
sobre o percurso mais adequado para apre- \\
ciação da exposição e sobre as áreas de \\
apoio (banheiros, por exemplo). \\
Recomendações \\
Instalar sinalização orientativa sobre o per- \\
curso mais adequado para apreciação da ex- \\
posição e sobre as áreas de apoio (ban- \\
heiros, por exemplo). \\
Normas Associadas \\
NBR 9050 (ABNT, 2015).
\end{tabular}

NBR 9050 (ABNT, 2015).

\section{Vigilância - Museu e Jardim}

\section{Diagnóstico}

Necessidade contratação e/ou realocação de funcionário(s) para fazer vigilância em turnos no museu, garantindo vigilância 24 horas por dia, protegendo tanto o patrimônio edificado quanto os itens do acervo exposto. Necessidade de instalação de detectores de metais e de guarda-volumes na entrada do museu.

\section{Recomendações}

Contratar e/ou realocar funcionário(s) para fazer vigilância em turnos no museu, garantindo vigilância 24 horas por dia, protegendo tanto o patrimônio edificado quanto os itens do acervo exposto. Instalar detectores de metais e guarda-volumes na entrada do museu.

\section{Normas Associadas}

Caderno de Segurança em Museus (IBRAM, 2011).

Sinalização de Emergência
Diagnóstico
Necessidade de sinalização da(s) rota(s) de
fuga.
Recomendações
Instalar sinalização da(s) rota(s) de fuga.
Normas Associadas
IT 11 (CB-SP, 2018), IT 20 (CB-SP, 2018), IT 40
(CB-SP, 2018), IT 43 (CB-SP, 2018). NBR 13434-1
(ABNT, 2004), NBR 13434-2 (ABNT, 2004), NBR
13434-3 (ABNT, 2018).

\section{Mapa de Diagnóstico e Recomendações MHCJ - Solar do Barão}

i. acessibilidade

IIII sinalização

.

$\Delta$ segurança contra incêndio

- segurança patrimonial

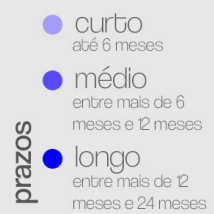

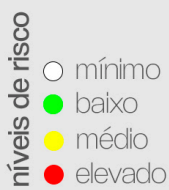

FAUUSP • FAPESP Bolsista IC: Raissa Melo de Souza Orientadora: Sheila Walbe Ornstein

Planta, diagnósticos e recomendaç̃es

Figura 13 - Mapa de diagnósticos e recomendações de segurança patrimonial e sinalização. Fonte: elaboração própria, 2018

O MHCJ também demanda, conforme pode-se observar nos mapas de danos e nos mapas de diagnósticos e de recomendações (figuras 6 a 13) pesquisas e monitoramentos continuados e específicos de sua cobertura e forros (elementos a serem 
substituídos), de trechos de piso do pavimento térreo, sobre o porão, a serem reforçados e escorados e acabamentos substituídos; da vedação frontal (em taipa) e das superfícies verticais de vedação internas, incluindo aquelas com pinturas decorativas relevantes de época, em estado de degradação e que apresentam fissuras e descolamentos.

Tanto o conjunto edificado e os jardins como os ambientes internos e os leiautes expositivos poderiam ser suportados nas ações de pesquisa combinadas, incluindo neste caso a implementação de APOs rotineiras, com projetos com vistas ao restauro e a salvaguarda do bem patrimoniado, pela modelagem BIM associada à internet das coisas, desde os levantamentos métricos e topográficos e os estudos preliminares de arquitetura até o cotidiano da gestão museológica. Há expertise nas universidades brasileiras (escolas de arquitetura e de engenharia) para dar apoio a iniciativas dessa natureza (no caso de equipamentos de monitoramento e do B(M), entendendo o $M H C$, por se tratar de um museu de pequeno porte, inserido numa rede de museus do município.

\section{CONSIDERAÇÕES FINAIS}

Os ambientes de qualquer natureza e uso, seja residencial ou comercial, empresarial ou industrial, no âmbito da saúde ou de caráter cultural, de acesso restrito ou público, necessitam de um plano de gestão continuada. Cada um, dentro do seu contexto, considerando as diversas funções e implicações. Da mesma forma os museus e especialmente aqueles abrigados em edificações antigas e construídas na sua origem para outras finalidades e tipos de uso.

Museus são ambientes concebidos principalmente para abrigar e apresentar a História de modo que os visitantes venham a conhecer ou se reconhecer no ambiente e nas exposições. Por isso, é função do arquiteto responsável, primordialmente, garantir a legibilidade e a funcionalidade do edifício, ou seja, o modo como a edificação é entendida pelos usuários dos ambientes em suas diferentes situações e o modo como o visitante se relaciona com aquele ambiente. Assim é necessário considerar os usuários dentro do contexto da gestão dos museus, de modo que seja feito um planejamento adequado ao público, considerando desde aspectos de acessibilidade e mobilidade, segurança, conforto, a até inteligibilidade das exposições. Nessa perspectiva, as interfaces entre a conservação do edifício antigo e as interfaces com os leiautes expositivos (museografia) têm grande importância e devem ser considerados e apoiar a gestão de riscos. 
Fica evidente, com base no exemplo aqui descrito, a necessidade de uma equipe multidisciplinar constituída também de arquitetos e engenheiros com prática em restauro de edifícios patrimoniados que atuem junto com conservadores com prática na conservação, por exemplo, de murais decorativos e de outros acervos móveis. As ações devem ser precedidas por pesquisas com vistas a implementação das melhores práticas.

Sobre o tema mais amplo da gestão das facilidades em ambientes museológicos, a APO tem a contribuir pois, através de seus instrumentos e protocolos, exemplificados neste artigo no objeto de estudo $M H C J$, é possível cruzar os resultados da avaliação de desempenho físico com a avaliação de satisfação dos usuários e traçar planos de ação com objetivos não só técnicos, mas também a fim de promover melhores condições de uso e experienciais aos usuários.

Uma desvantagem da APO é que o resultado final se dá na forma de diretrizes, mas não, necessariamente, em projetos para o ambiente avaliado. As diretrizes por si sós não são capazes de solucionar os problemas encontrados de forma técnico-espacial. Uma vez que a avaliação de desempenho físico é feita por um profissional qualificado ou uma equipe multidisciplinar de especialistas, seria pertinente que os resultados e as diretrizes decorrentes da APO se transformassem efetivamente em projetos arquitetônicos elaborados por esses especialistas, levando em consideração as normas, instruções técnicas e legislações pertinentes que embasaram as recomendações prévias. Desse modo, o ciclo sistêmico se completaria, sendo possível aplicar novamente a APO ao mesmo objeto de estudo, após a realização das melhorias pontuadas, e retroalimentar o processo de modo continuado.

Em síntese, as APOs, baseadas em pesquisas rigorosas, podem colaborar com os diagnósticos e as recomendações mais assertivas em casos de ambientes com esta complexidade e se tornar ferramentas de ação sistêmica voltadas à manutenção preventiva se gestores públicos e privados, profissionais técnicos e prestadores de serviço envolvidos trabalharem na plataforma BIM, de forma compartilhada e simultânea.

\section{AGRADECIMENTOS}

À Fundação de Amparo à Pesquisa do Estado de São Paulo (FAPESP) pela concessão bolsa de Iniciação Científica a Raissa Melo de Souza, no período 2018-2019, processo número 2017/19274-4. 
Ao Conselho Nacional de Desenvolvimento Científico e Tecnológico (CNPq) pela concessão de bolsa produtividade a Sheila Walbe Ornstein, no período 2017-2021, processo número 301406/2016-2.

À direção e à equipe do Museu Histórico e Cultural de Jundiaí - Solar do Barão pela autorização e oportunidade de realização de pesquisa no seu interior e jardins.

Ao Condephaat, à UPPH, ao DPHC de Jundiaí e à Prefeitura Municipal de Jundiaí pelas contribuições com a pesquisa. 


\section{REFERÊNCIAS}

\section{LIVROS, ARTIGOS E TESES}

ASSIS, Elisa Prado de. Acessibilidade nos bens culturais imóveis: possibilidades e limites nos museus e centros culturais. 2012. Dissertação (Mestrado) - Faculdade de Arquitetura e Urbanismo da Universidade de São Paulo, São Paulo, 2012.

ASSOCIAÇÃO BRASILEIRA DE NORMAS TÉCNICAS. NBR 9050 - Acessibilidade a edificações, mobiliário, espaços e equipamentos urbanos. Rio de Janeiro, 2015.

ASSOCIAÇÃO BRASILEIRA DE NORMAS TÉCNICAS. NBR 15575-1 - Edificações habitacionais - Desempenho. Parte 1: Requisitos gerais. Rio de Janeiro, 2013 a.

ASSOCIAÇÃO BRASILEIRA DE NORMAS TÉCNICAS.NBR 15575-2 - Edificações habitacionais - Desempenho. Parte 2: Requisitos para os sistemas estruturais. Rio de Janeiro, $2013 \mathrm{~b}$.

ASSOCIAÇÃO BRASILEIRA DE NORMAS TÉCNICAS. NBR 15575-3 - Edificações habitacionais - Desempenho. Parte 3: Requisitos para os sistemas de pisos. Rio de Janeiro, 2013c.

ASSOCIAÇÃO BRASILEIRA DE NORMAS TÉCNICAS. NBR 15575-4 - Edificações habitacionais - Desempenho. Parte 4: Requisitos para os sistemas de vedações verticais internas e externas. Rio de Janeiro, $2013 \mathrm{~d}$.

ASSOCIAÇÃO BRASILEIRA DE NORMAS TÉCNICAS. NBR 15575-5 - Edificações habitacionais - Desempenho. Parte 5: Requisitos para os sistemas de coberturas. Rio de Janeiro, 2013e.

ASSOCIAÇÃO BRASILEIRA DE NORMAS TÉCNICAS. NBR 15575-6 - Edificações habitacionais - Desempenho. Parte 6: Requisitos para os sistemas hidrossanitários. Rio de Janeiro, $2013 \mathrm{f}$.

ASSOCIAÇÃO BRASILEIRA DE NORMAS TÉCNICAS. NBR 16537 - Acessibilidade - Sinalização tátil no piso - Diretrizes para a elaboração de projetos e instalação. Rio de Janeiro, 2018.

ASSONI, Aline Dias; ORNSTEIN, Sheila Walbe. Museus interativos sob a ótica dos usuários. Avaliação Pós-Ocupação aplicada no caso do Museu Catavento, SP. Cadernos do PROARQ [on-line]. Rio de Janeiro, Faculdade de Arquitetura e Urbanismo da Universidade Federal do Rio de Janeiro, n. 33, p. 111-132, dez. 2019. Disponível em: <https://bit.ly/2uHliMo>. Acesso em: 27 fev. 2020. 
BARROS, Natália Nakamura; RUSCHEL, Regina Coeli; SILVA, Vanessa Gomes. Esquema conceitual de Internet das Coisas para ACV na fase de uso de edificações. Anais do II Simpósio Brasileiro de Tecnologia de Informação e Comunicação na Construção Civil. Virtualização Inteligente no Projeto e na Construção. Campinas: UNICAMP, Associação Nacional de Tecnologia do Ambiente Construído, 19-21 de agosto de 2019. Disponível em: <https://bit.ly/32wDQLA>. Acesso em: 25 ago. 2019.

BERMÚDEZ, Ana Carla. Incêndio na catedral de Notre-Dame já dura 3h, e parte da estrutura desaba. Disponível em: <https://bit.ly/2T5narp>. Acesso em: 12 jun. 2019.

BIENVENIDO-HUERTAS, David; NIETO-JULIÁN, Juan Enrique; MOYANO, Juan José; MACÍASBERNAL, Juan Manuel; CASTRO, José. Implementing Artificial Intelligence in H-BIM Using the J48 Algorithm to Manage Historic Buildings. International Journal of Architectural Heritage [on-line], 23 mar. 2019. Disponível em: <https://bit.ly/2uCaTl3>. Acesso em: 27 jun. 2019.

CARVALHO, Claudia Soares Rodrigues de. Conservação preventiva de edifícios e sítios históricos: pesquisa e prática. Revista CPC. n. 18, p. 141-153, dez. 2014-abr. Disponível em: <https://bit.ly/2TqiCLe>. Acesso em: 25 out. 2019.

COHEN, Regina; DUARTE, Cristiane Rose de Siqueira; BRASILEIRO, Alice de Barros Horizonte. Acessibilidade a Museus. Brasília, DF: MinC/Ibram, 2012. Cadernos Museológicos v. 2.

CORPO DE BOMBEIROS DO ESTADO DE SÃO PAULO. Legislação - Consulta. São Paulo, $2018 \mathrm{a}$.

CORPO DE BOMBEIROS DO ESTADO DE SÃO PAULO. Instrução Técnica O6 - Acesso da viatura na edificação. São Paulo, 2018b.

CORPO DE BOMBEIROS DO ESTADO DE SÃO PAULO. Instrução Técnica 08 - Segurança estrutural contra incêndio. São Paulo, 2018c.

CORPO DE BOMBEIROS DO ESTADO DE SÃO PAULO. Instrução Técnica 10 - Controle de materiais de acabamento e de revestimento. São Paulo, 2018d.

CORPO DE BOMBEIROS DO ESTADO DE SÃO PAULO. Instrução Técnica 11 - Saídas de emergência. São Paulo, 2018e.

CORPO DE BOMBEIROS DO ESTADO DE SÃO PAULO. Instrução Técnica 17 - Brigada de incêndio. São Paulo, $2018 \mathrm{f}$.

CORPO DE BOMBEIROS DO ESTADO DE SÃO PAULO. Instrução Técnica 19 - Sistema de detecção e alarme de incêndio. São Paulo, 2018g. 
CORPO DE BOMBEIROS DO ESTADO DE SÃO PAULO. Instrução Técnica 20 - Sinalização de Emergência. São Paulo, 2018h.

CORPO DE BOMBEIROS DO ESTADO DE SÃO PAULO. Instrução Técnica 21 - Sistema de proteção por extintores de incêndio. São Paulo, $2018 \mathrm{i}$.

CORPO DE BOMBEIROS DO ESTADO DE SÃO PAULO. Instrução Técnica 22 - Sistema de hidrantes e mangotinhos para combate a incêndio. São Paulo, 2018j.

CORPO DE BOMBEIROS DO ESTADO DE SÃO PAULO. Instrução Técnica 40 - Edificações históricas, museus e instituições culturais com acervos museológicos. São Paulo, 2018k.

CORPO DE BOMBEIROS DO ESTADO DE SÃO PAULO. Instrução Técnica 43 - Adaptação às normas de segurança contra incêndio - Edificações existentes. São Paulo, 20181.

EVIDENCE-BASED DESIGN. A Visual Reference for Evidence-Based Design. Disponível em: <https://bit.ly/2I3NL1W>. Acesso em: 17 nov. 2019.

FINCH, Edward (editor). Facilities Change Management. Oxford, UK: Wiley-Blackwell, 2012.

FRANÇA, Ana Judite Galbiatti Limongi. Ambientes contemporâneos para o ensinoaprendizagem: avaliação pós-ocupação aplicada a três edifícios escolares públicos, situados na região metropolitana de São Paulo. 2011. Dissertação (Mestrado) -Faculdade de Arquitetura e Urbanismo da Universidade de São Paulo, São Paulo, 2011.

FUNDAÇÃO DARCY RIBEIRO. O Jardim de Rui Barbosa. Preservação de um Jardim Histórico. Rio de Janeiro: Fundação Darcy Ribeiro, 2017.

G1. Incêndio atinge Museu da Língua Portuguesa em SP, dizem bombeiros. São Paulo, 21 dez. 2015. Disponível em: <https://glo.bo/2HZP2ac>. Acesso em: 13 maio 2019.

G1. O que se sabe sobre o incêndio no museu nacional no Rio. Rio de Janeiro, 4 ago. 2018. Disponível em: <https://glo.bo/2PvU1U5>. Acesso em: 13 maio 2019.

KOWALTOWSKI, Doris Catherine Cornelie Knatz. MOREIRA, Daniel de Carvalho. O programa de necessidades e a importância de APO no processo de projeto. Fortaleza, ENTAC, 2008. Disponível em: <https://www.dkowaltowski.net/920.pdf>. Acesso em: 23 jun. 2018.

LOPES, Sofia; ORNSTEIN, Sheila Walbe. O Potencial da Avaliação Pós-Ocupação (APO) para a preservação de ambientes museológicos localizados em edifícios antigos: o caso do 
Museu da Imigração, SP. Projetar. Projeto e Percepção do Ambiente. Natal, v. 3, n. 2, p. 67-79, 2018. Disponível em: <https://bit.ly/2VrzgwC>. Acesso em: 20 out. 2019.

ONO, Rosaria. MOREIRA, Kátia Beatris. Segurança em Museus. Brasília: IBRAM, 2011.

ONO, Rosaria; ORNSTEIN, Sheila Walbe; VILLA, Simone Barbosa; FRANÇA, Ana Judite Galbiatti Limongi. (orgs). Avaliação Pós-Ocupação na Arquitetura, no Urbanismo e no Design: da Teoria à Prática. São Paulo: Oficina de Textos, 2018.

ORNSTEIN, Sheila Walbe. Avaliação Pós-Ocupação no Brasil, 30 anos: o que há de novo? São Paulo: Revista Projetar. Projeto e Percepção do Ambiente, 2017a. v.2, p. 7-12. Disponível em: <https://bit.ly/2T16Zp4>. Acesso em: 27 out. 2019.

ORNSTEIN, Sheila Walbe. Com os usuários em mente: um desafio para a boa prática arquitetônica. Campinas: PARC. Pesquisa em Arquitetura e Construção, 2017b, v.7, n. 3, p. 189-197. Disponível em: <https://bit.ly/32wLl5g>. Acesso em: 27 out. 2019.

PARAIZO, Rodrigo Cury. Realidade Virtual. In: BRAIDA, F. et al. (orgs.). 101 Conceitos de Arquitetura e Urbanismo na Era Digital. São Paulo: ProBooks, 2016. p. 170-171.

PASCOAL JÚNIOR, Jairo et al. Influência dos parâmetros de aquisição de imagens com auxílio de drone para geração de nuvem de pontos de obras civis. Anais do II Simpósio Brasileiro de Tecnologia de Informação e Comunicação na Construção Civil. Virtualização Inteligente no Projeto e na Construção. Campinas: UNICAMP, Associação Nacional de Tecnologia do Ambiente Construído, 19-21 ago. 2019. Disponível em: <https://bit.ly/2T3rzeu>. Acesso em: 25 ago. 2019.

PENTEADO, Ana Paula Bonini; IAROZINSKY NETO, Alfredo; PENTEADO, Ana Carolina Bonini. A relação entre o conforto perceptivo e a caracterização do espaço com ênfase em ambientes internos. São Paulo: Revista Pós, Faculdade de Arquitetura e Urbanismo da Universidade de São Paulo, v. 25. n. 45. p. 150-168, 2018. Disponível em: <https://bit. 1y/382z0ah>. Acesso em: 20 out. 2019.

PINHEIRO, José de Queiroz; GÜNTHER, Hartmut. (orgs). Métodos de Pesquisa nos Estudos Pessoa-Ambiente. São Paulo: Casa do Psicólogo, 2008.

PONTIM, Carolina, et al. Cartilla 2017. Gestión de Riesgos al Patrimonio Musealizado Brasileño. Brasília, DF: MinC/IBRAM, 2017.

PRESIDÊNCIA DA REPÚBLICA. SECRETARIA GERAL. Decreto no 9.983 de 22 de agosto de 2019. Dispõe sobre a estratégia nacional do BIM e institui o Comitê Gestor da Estratégia do BIM. Disponível em: <https://bit.ly/2TsMkj0>. Acesso em: 28 ago. 2019. 
QUINELLO, Robson; NICOLETTI, José Roberto. Gestão de Facilidades. São Paulo: Novatec, 2006.

REYES, Jorge Garcia; CAMPOS, Diego Echeverry; HERNÃNDEZ, Harrison Mesa. Gerencia de proyectos. Aplicación a proyectos de construcción de edificaciones. Bogotá: Universidad de Los Andes, Faculdad de Ingeniería Civil e Ambiental, 2017.

RHEINGANTZ, Paulo Afonso et al. Observando a qualidade do lugar: Procedimento para a avaliação pós-ocupação. Rio de Janeiro: PROARQ/FAU-UFRJ, 2009.

RODRIGUES, Helena S.; CASTRO, Jorge A.; RHEINGANTZ, Paulo A. Matriz de Descobertas: uma ferramenta para a Avaliação Pós-Ocupação. NUTAU'2004, São Paulo. In: Anais. São Paulo: NUTAU/USP, 2004. (CD-ROM).

SOUZA, Raissa Melo de. O Sistema Construtivo e a Funcionalidade de um Espaço Museológico abrigado em um edifício antigo de valor histórico sob a perspectiva da Avaliação Pós-Ocupação (APO). Relatório Final de Pesquisa de Iniciação Científica. São Paulo: Faculdade de Arquitetura e Urbanismo da Universidade de São Paulo / Fundação de Amparo à Pesquisa do Estado de São Paulo, 2019. Processo no. 2017/19274-4. 179p.

TINOCO, Jorge Eduardo Lucena. Mapa de danos e recomendações básicas. Olinda: Centro de Estudos Avançados da Conservação Integrada (CECI). Textos para discussão, v. 43. 2009.

VOORDT, Theo J. M. van der. WEGEN, Herman B. R. van. Arquitetura sob o olhar do usuário. São Paulo: Oficina de textos, 2013.

ZEISEL, John. Inquiry by Design. Environment / Behavior/ Neuroscience in Architecture, Interiors, Landscape, and Planning. Nova York: W.W. Norton, 2006.

Artigo apresentado em 10/07/2019. Aprovado em 16/12/2019.

\section{(cc) BY}

All the contents of this journal, except where otherwise noted, is licensed under a Creative Commons Attribution License 